\title{
Ultrasonography of Pediatric Superficial Soft Tissue Tumors and Tumor-Like Lesions
}

\author{
Hae Won Kim, $M D^{1,2}$, So-Young Yoo, $M D, \mathrm{PhD}^{1}$, Saelin 0 h, $\mathrm{MD}^{1,3}$, Tae Yeon Jeon, $M D, \mathrm{PhD}^{1}$, \\ Ji Hye Kim, MD, PhD ${ }^{1}$ \\ ${ }^{1}$ Department of Radiology, Sungkyunkwan University School of Medicine, Samsung Medical Center, Seoul, Korea; ${ }^{2}$ Department of Radiology, College \\ of Medicine, The Catholic University of Korea, Seoul, Korea; ${ }^{3}$ Department of Radiology, Korea University Medical Center, Seoul, Korea
}

Ultrasonography (US) is usually the first imaging examination performed to evaluate palpable or visible superficial soft tissue lesions that are common in children. Although clinical assessments, such as age at presentation, clinical course, and overlying skin discoloration, are important for the differentiation of pediatric soft tissue lesions, US allows a specific diagnosis of some typical benign lesions and helps in guiding further investigation since it provides detailed information about the lesion location, characterization including solid versus cystic, vascularity, and compressibility. Therefore, sufficient knowledge of the normal anatomy, proper ultrasonographic techniques, and the imaging findings of common and uncommon soft tissue lesions in children are crucial for accurate assessment and management of patients. In this article, we review the techniques and imaging findings focusing on the ultrasonographic features of a variety of superficial soft tissue lesions detected in children.

Keywords: Ultrasonography; MRI; Soft-tissue lesion; Soft-tissue tumor; Children

\section{INTRODUCTION}

Although most of the superficial soft-tissue lesions in children are benign, clinical findings are often nonspecific, requiring further imaging evaluation $(1,2)$. Ultrasonography (US) is usually the initial study requested and has many benefits such as easy accessibility, no need for sedation, lack of radiation and superior resolution for soft tissue lesion (3-5). While some soft-tissue lesions can readily be diagnosed by clinical information and typical US findings, most of the solid lesions are non-specific and US can be used to determine the necessity of additional imaging such as MRI, and/or biopsy or surgical resection, and whether it can be left alone or followed $(3,6)$.

Received May 20, 2019; accepted after revision October 29, 2019. Corresponding author: So-Young Yoo, MD, PhD, Department of Radiology, Sungkyunkwan University School of Medicine, Samsung Medical Center, 81 Irwon-ro, Gangnam-gu, Seoul 06351, Korea.

- Tel: (822) 3410-0511 - Fax: (822) 3410-0084

- E-mail:sy1131.yoo@samsung.com

This is an Open Access article distributed under the terms of the Creative Commons Attribution Non-Commercial License (https://creativecommons.org/licenses/by-nc/4.0) which permits unrestricted non-commercial use, distribution, and reproduction in any medium, provided the original work is properly cited.
In this article, we review the ultrasonographic technique and imagining findings of common and uncommon superficial soft-tissue lesions encountered in the pediatric population.

\section{US Technique for Evaluation of Superficial Soft-Tissue Lesions}

Before starting an US scan, it may be helpful to check the appearance of the lesion such as skin color change in well-illuminated environment and verify the clinical history, including age of onset, time course of the lesion, multiplicity, and symptoms (4).

Superficial soft-tissue lesions should be examined using a high frequency (> $10 \mathrm{MHz}$ ) linear transducer for maximal spatial resolution of superficial structures and detailed information of the layers of skin and subcutaneous tissues (Fig. 1). US parameters including gain, time gain compensation, depth and number of the focal zones, frequency, gray scales, and dynamic range must be properly optimized $(4,5)$. It is important not to distort the lesion by applying sufficient amount of gel on the lesion and not pressing the lesion excessively.

Echogenicity of the lesion should be compared to the 
adjacent subcutaneous fat or muscle $(7,8)$. US is very helpful in differentiating between cystic and solid lesion. An anechoic mass with posterior acoustic enhancement is the hallmark of a cystic lesion. Also, when pressed with a probe, cystic lesions are better pressed than solid lesions, although some cystic lesions do not deform on compression (7). Color Doppler scan is needed to confirm the vascular, solid or cystic nature of a mass. The sensitivity of the color Doppler scan can be improved by decreasing the scale level or pulse repetition frequency, increasing the color gain until color noise appears, and decreasing probe pressure on the lesion to avoid compressing small vessels. Spectral Doppler scan includes the type of waveform (arterial or venous), the magnitude of velocities, and resistive index (8).

\section{Vascular Tumors}

According to the International Society for the Study of Vascular Anomalies (ISSVA) classification for vascular

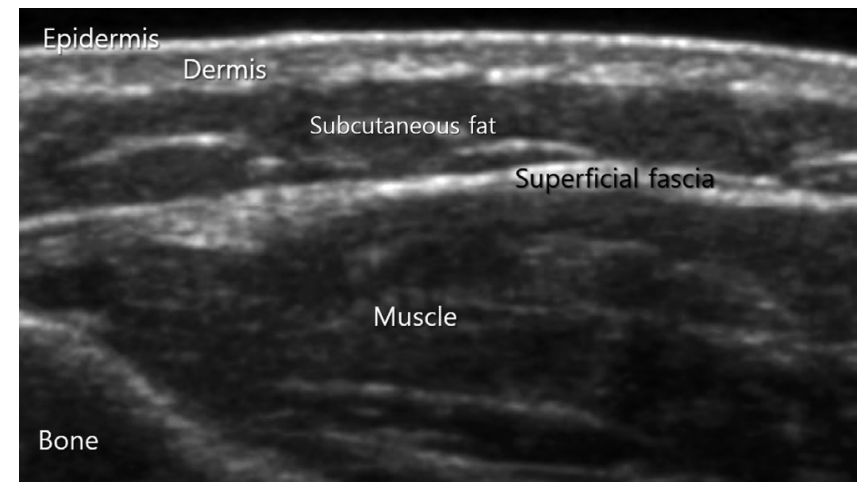

Fig. 1. Visualization of normal soft tissue structure at dorsal aspect of forearm by US. US = ultrasonograpy

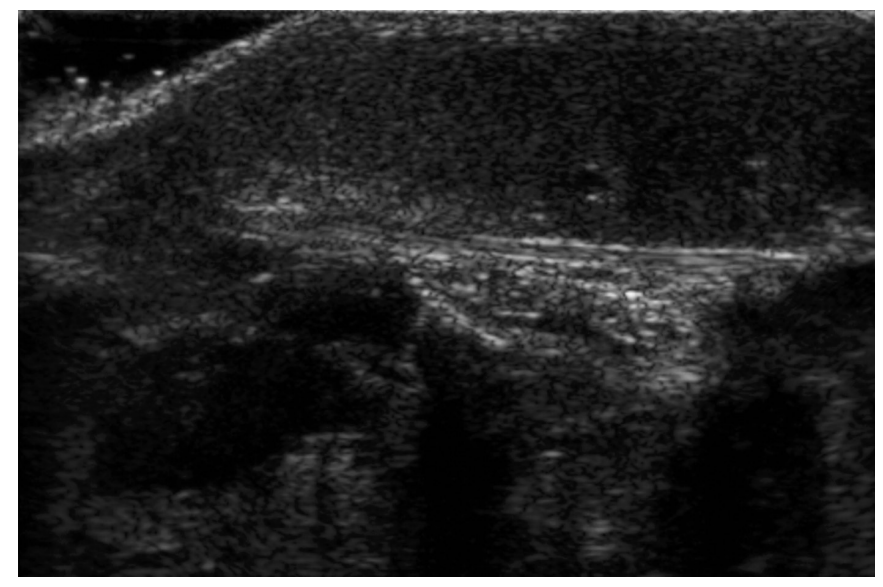

A

Fig. 2. Infantile hemangioma in 8-month-old girl with enlarging foot mass.

US (A) shows well-defined ovoid hypoechoic mass confined to subcutaneous fat. Color Doppler scan (B) shows increased vascular flow. anomalies, which updated in 2018, vascular anomalies are divided into vascular tumors and vascular malformations (9, 10).

Vascular tumors can be classified as benign, locally aggressive or borderline, and malignant $(9,10)$. Benign vascular tumors include infantile hemangioma, congenital hemangioma, tufted angioma, and lobular capillary hemangioma (9). Infantile hemangioma is not present at birth and may begin to grow in the first week to months, reaching its maximum size at 1 year of age followed by slow involution $(11,12)$. On US, an infantile hemangioma during the proliferative phase usually appears as a well-defined mass located in subcutaneous tissue showing variable echogenicity and color Doppler shows increased internal vascular flow (Fig. 2) (12). After reaching its maximum size, the infantile hemangioma starts an involuting phase characterized by decrease in size, increase in echogenicity and decrease of internal vascular flow as a result of fibrofatty replacement $(10,12)$.

Congenital hemangiomas are present at birth by definition $(11,12)$. According to their behavior after birth, congenital hemangiomas are classified as rapidly involuting congenital hemangioma (RICH), non-involuting congenital hemangioma (NICH), or partially involuting congenital hemangioma (PICH) $(9,12)$. Compared to infantile hemangioma, congenital hemangioma is relatively rare, negative for glucose transporter 1 (GLUT1) and, at US, more often show inhomogeneous echogenicity with relatively large intralesional vessels, which are visible on gray-scale imaging (Fig. 3) (10, 12).

Lobular capillary hemangioma is common in patients older than 6 months and most of the lesions can be diagnosed

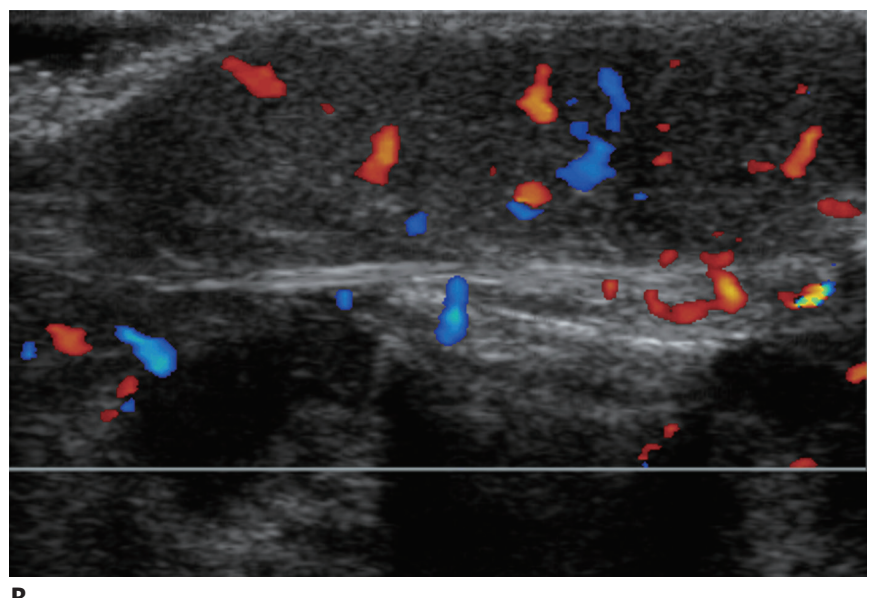

B 
clinically. They present as a rapidly growing vascular skin lesion with bleeding (12). On US, they tend to be small in size, hypoechoic compared to subcutaneous fat and show increased vascular flow with high velocity on color Doppler scans (Fig. 4) (12, 13).

Kaposiform hemangioendothelioma is a locally aggressive vascular neoplasm with infiltrative growth pattern, composed of spindle-shaped endothelial cells, and abnormal lymphatics. It mostly affects infants and commonly appears as a growing, red to purple plaque, which can be tender $(10,12)$. On US, it appears as an ill-defined, heterogeneous lesion and can be focal or diffuse, confined to subcutaneous fat or involving all soft-tissue planes (Fig. 5) (10, 12). It may be associated in cases more than $50 \%$ with profound sustained consumptive coagulopathy (Kasabach-Merritt phenomenon) $(10,12,14)$.

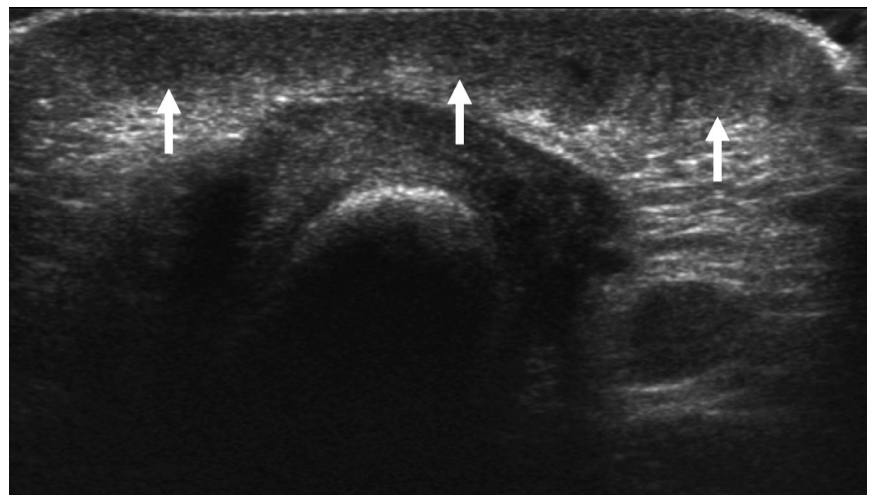

A

Fig. 3. Congenital hemangioma in 2-day-old boy at knee present at birth.

US (A) shows homogeneous hypoechoic lesion in subcutaneous fat layer (arrows). Color Doppler scan (B) shows markedly increased vascular flow.
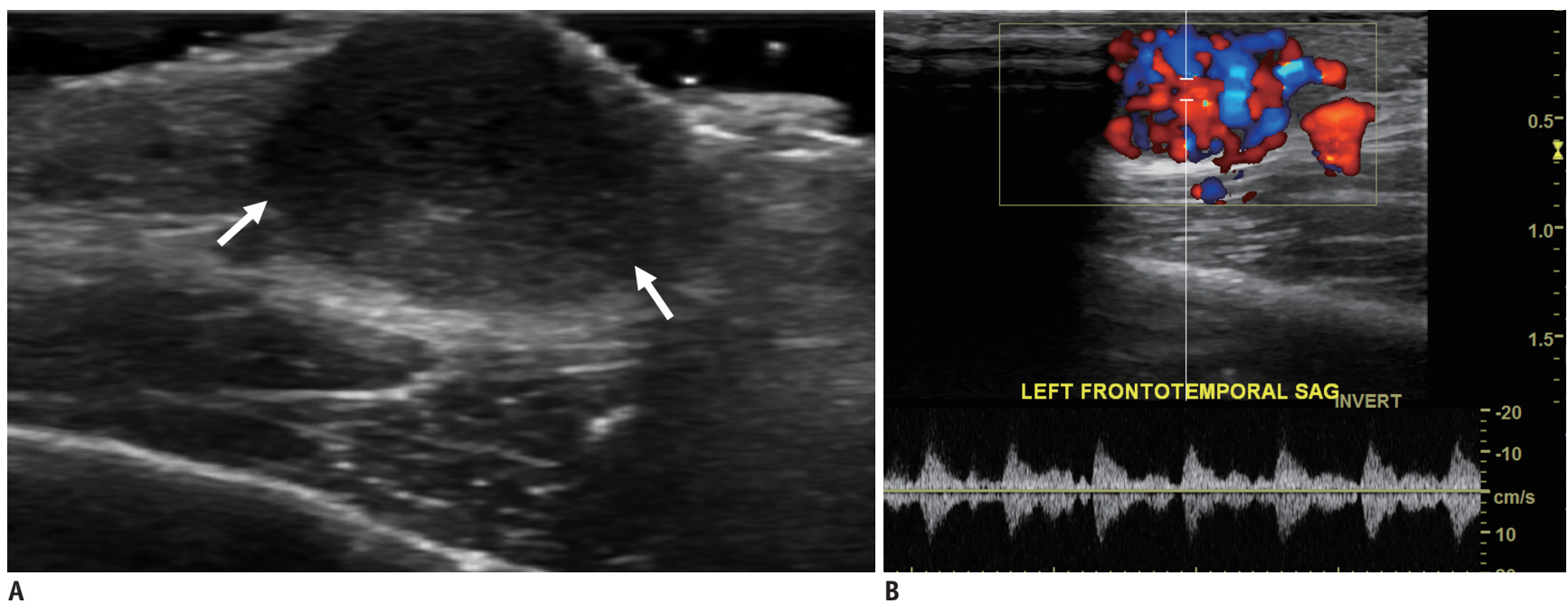

A

Fig. 4. Lobular capillary hemangioma in 13-year-old girl with enlarging soft tissue mass at scalp.

US (A) shows well-defined slightly heterogeneous hypoechoic nodule on skin and subcutaneous fat layer (arrows). Color Doppler scan (B) shows increased vascular flow within nodule. 

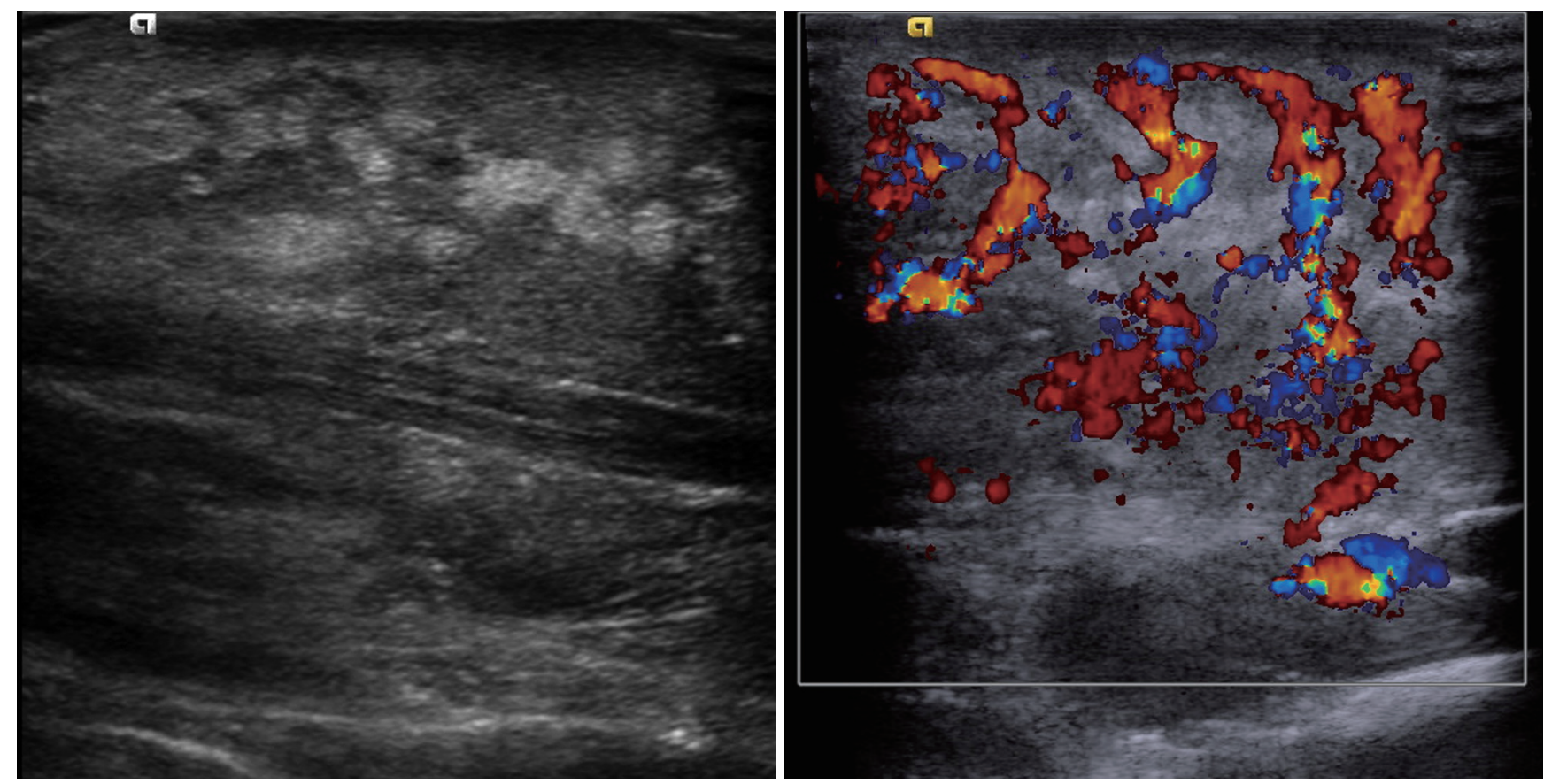

A

\section{B}
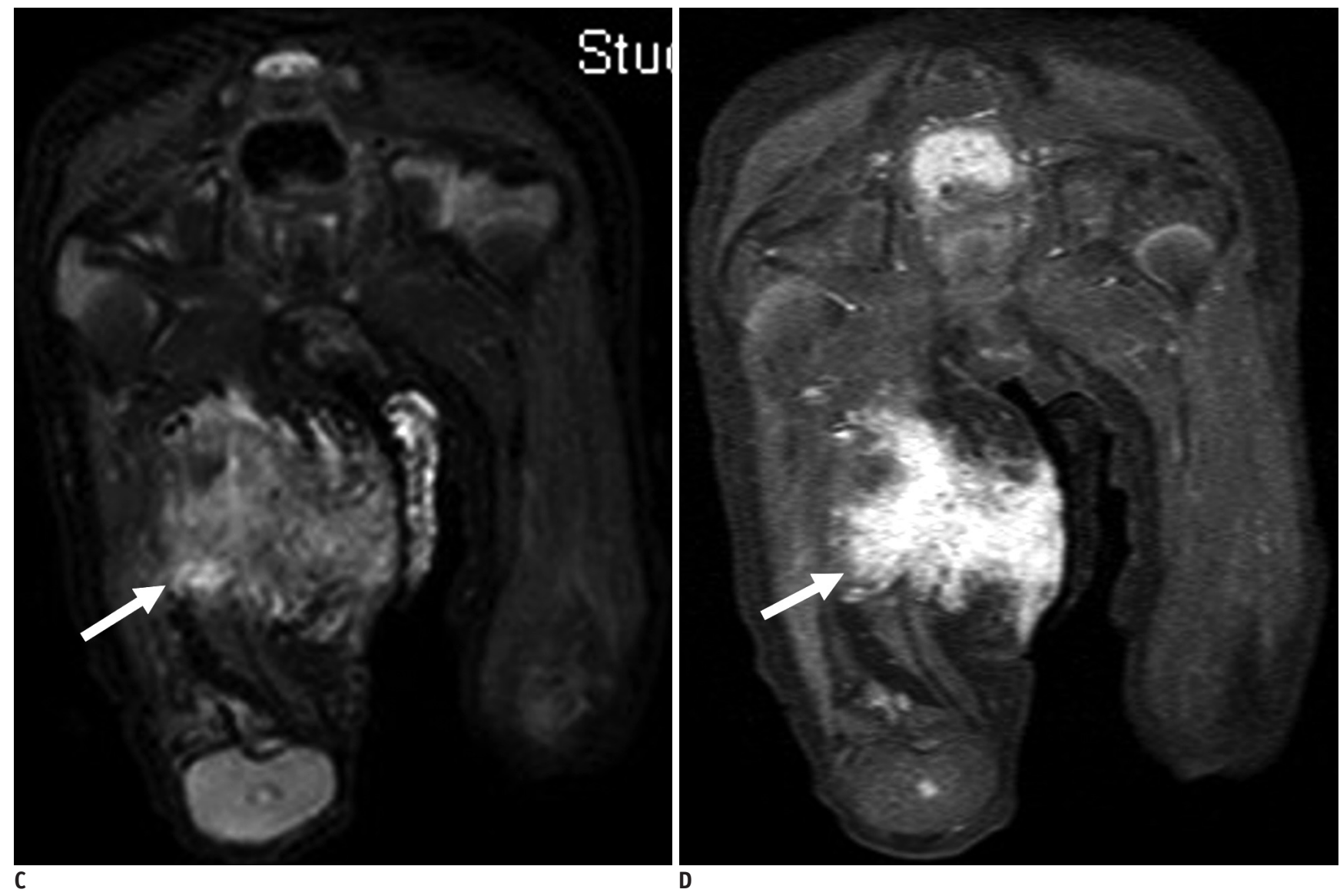

Fig. 5. Kaposiform hemangioendothelioma at right thigh in 2-day-old girl with Kasabach-Merritt phenomenon.

US (A) shows large ill-defined heterogeneous mass, which infiltrates subcutaneous tissue and underlying musculature with marked skin thickening. Color Doppler scan (B) shows increased vascular flow with high velocity of lesion. Coronal fat-suppressed T2-weighted MRI (C) shows heterogeneous high signal intensity mass (arrow). Contrast-enhanced coronal fat-suppressed T1-weighted MRI (D) shows prominent enhancement of mass (arrow). 
velocity, although it is not uncommon to have difficulty demonstrating intralesional vascularity in actual practice (17).

Lymphatic malformation (LM) can be divided into macrocystic, microcystic, and mixed types (20). Macrocystic lesions which are composed of cysts larger than 1-2 cm appear as multiseptated cysts on US (Fig. 7) and effectively decrease in size with aspiration or sclerotherapy (20). While venous spaces in a VM can be collapsed with compression, cystic spaces in a LM can be deformed but usually do not entirely collapse with compression (15). Microcystic LM often appears as solid hyperechoic lesions due to numerous tiny cysts that are too small to be seen by probe resolution and some scattered cysts may also be seen (17).

\section{Adipocytic Tumors and Other Fat-Containing Mass-Like Lesions}

US finding of fat-containing lesions can vary depending on the proportion of fat component. While lesions composed of pure fat tend to be hypoechoic on US, lesions with a mixture of fat and other soft-tissue components show increased echogenicity (21). Therefore, MRI including fat suppression sequences is often needed to confirm the

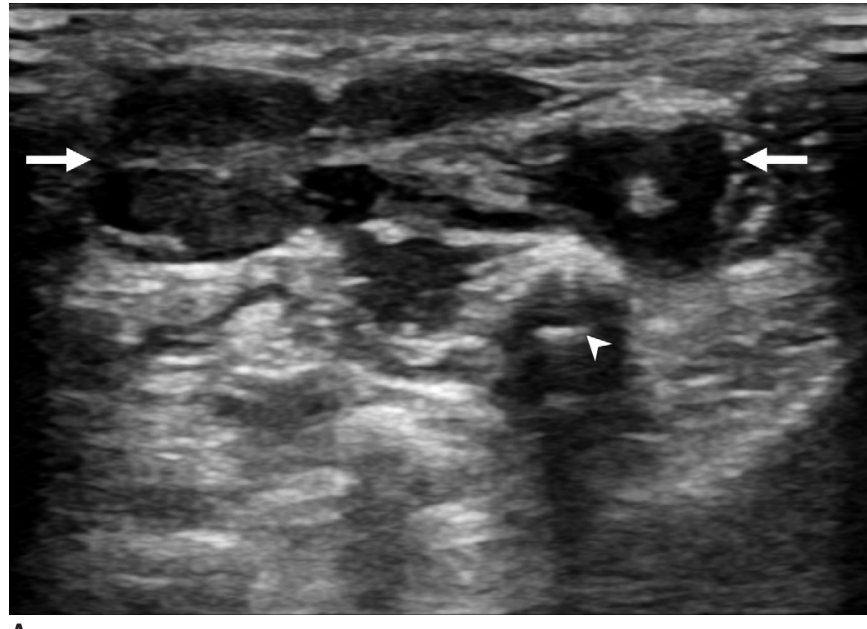

A

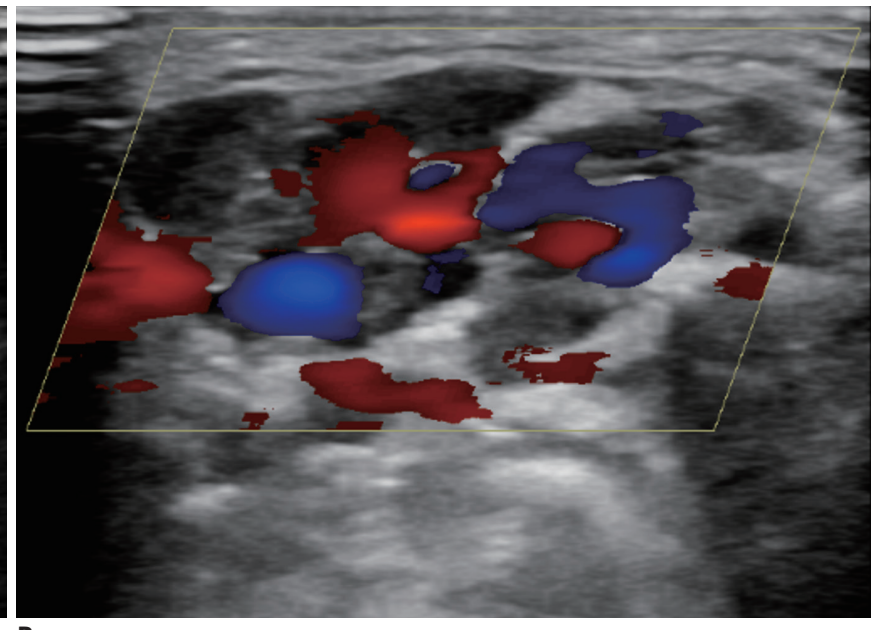

B

Fig. 6. Venous malformation in 9-year old boy presented with mass in hand.

US (A) shows inter-/intra-muscular lesion containing anechoic serpentine structure (arrows) with increased internal echogenicity due to slow blood flow. There is focal hyperechoic lesion with posterior acoustic shadowing, suggesting phlebolith (arrowhead). Color Doppler scan (B) shows venous flow.

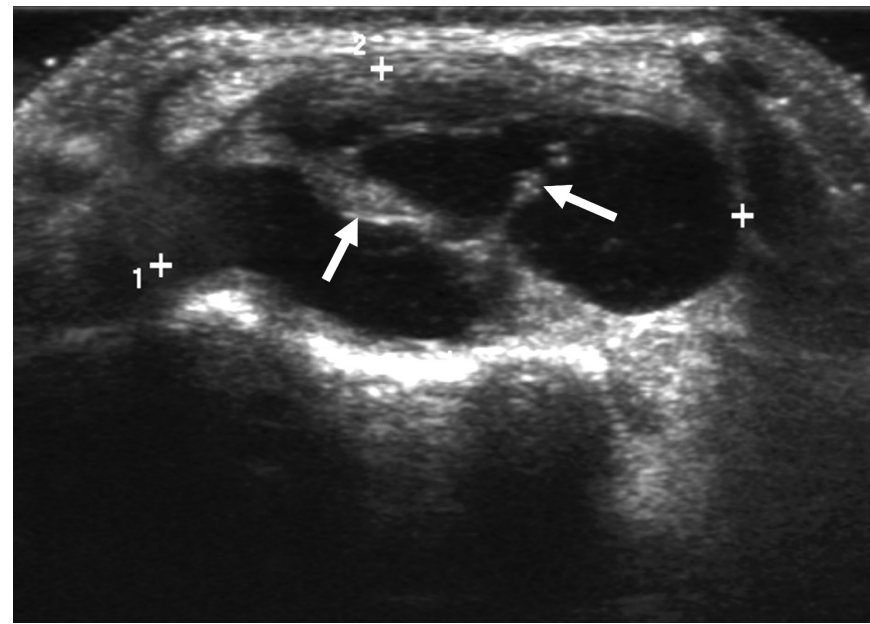

A

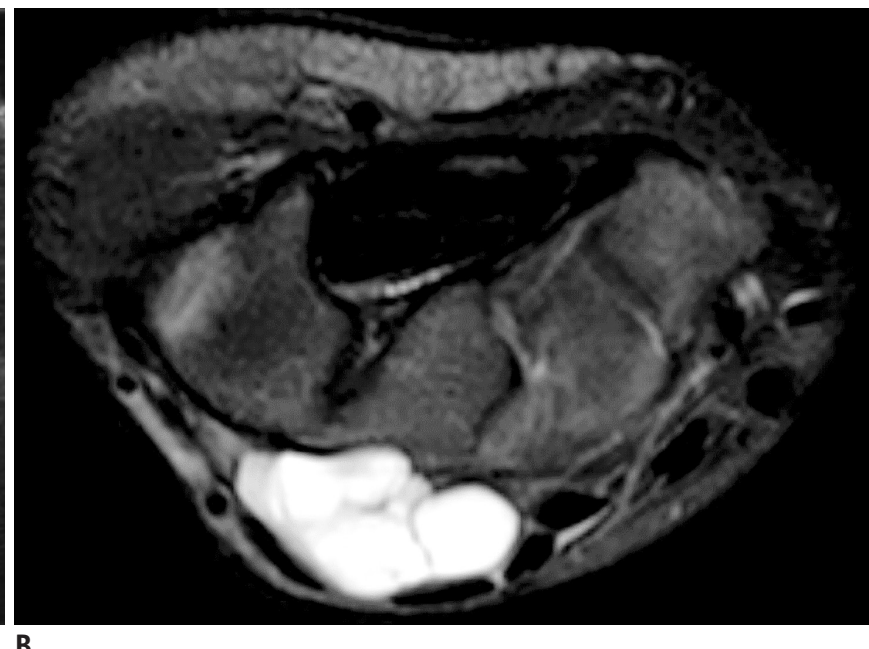

B

Fig. 7. Lymphatic malformation in 9-year-old girl with palpable mass at wrist dorsum.

US (A) shows multiloculated cyst (between cursors) in subcutaneous fat layer with internal septa (arrows) and some echogenic debris. Axial fatsuppressed T2-weighted image (B) shows multiloculated cyst with internal septa. 
presence of fat within a lesion.

Although lipoma composed of mature fat is common in the adult, it comprises only $4 \%$ of all soft-tissue tumor in children (22). On US, lipomas show various appearances depending on the composition ratio of the intralesional fat and water and tumor location. It usually appears as a homogeneous mass with variable echogenicity relative to adjacent structure (Fig. 8) $(4,21)$.

Lipoblastoma, a benign tumor composed of both mature and immature adipocytes, occurring typically within the first 3 years of age, is the second most common adipocytic tumor accounting for about $30 \%$ and it often presents in the extremities with varying size $(4-13 \mathrm{~cm})(3,21,23) .0 \mathrm{n}$ US, lipoblastoma appears as a well-defined, predominantly homogeneous hyperechoic mass (Fig. 9), though it can be hypoechoic or isoechoic or mixed echogenic lesions with

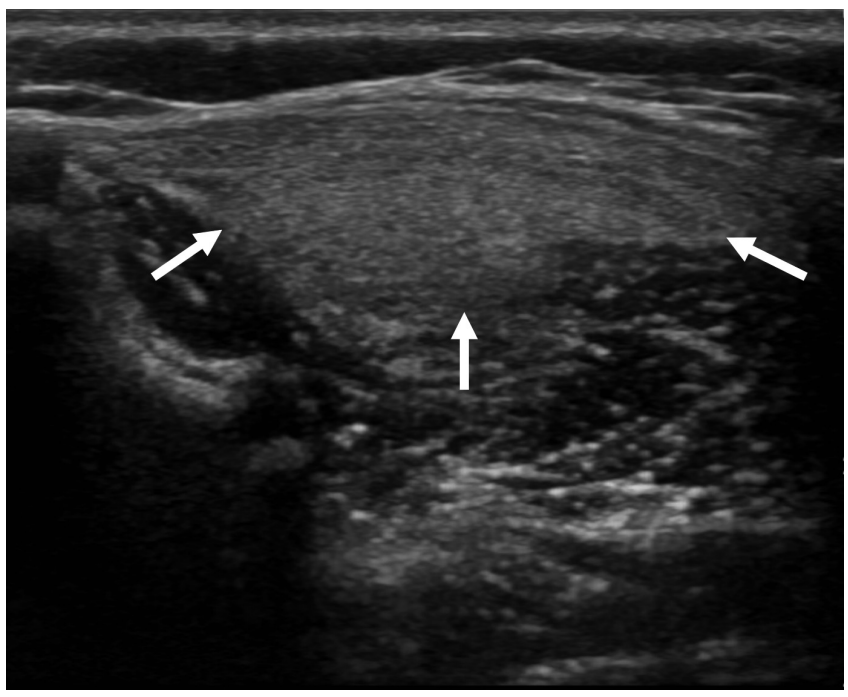

Fig. 8. Lipoma in 9-month-old girl with lump on back. US shows ill-defined ovoid hyperechoic mass (arrows) confined within right paravertebral muscle. some internal cystic spaces due to variable components including fibro-myxoid components (21). They tend to be encapsulated with internal septa on MRI (23-25).

Subcutaneous fat necrosis is a benign entity that can often present with a palpable subcutaneous nodule of the torso or extremities $(21,26)$. They can appear as a welldefined, isoechoic mass with a surrounding hypoechoic halo or a poorly defined hyperechoic lesion on US (Fig. 10) (21, 27). Subcutaneous fat necrosis of the newborn is a rare, transient complication of birth asphyxia, hypothermia, and trauma. It is usually self-limiting condition but may result in serious complication such as hypercalcemia (26).

\section{Fibroblastic and Myofibroblastic Lesions}

Nodular fasciitis is an uncommon benign lesion, which grows rapidly due to local fibrous proliferation, accompanied by pain and can be mistaken for a malignant

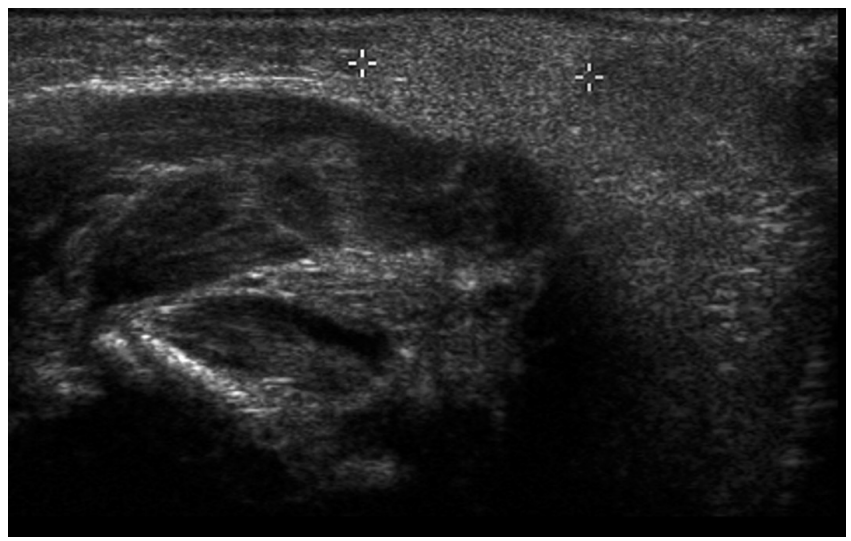

Fig. 10. Subcutaneous fat necrosis of newborn in 1-monthold boy with small palpable mass at posterior neck. US shows homogeneous echogenic nodule (between cursors) at subcutaneous fat layer without cystic changes or calcification.

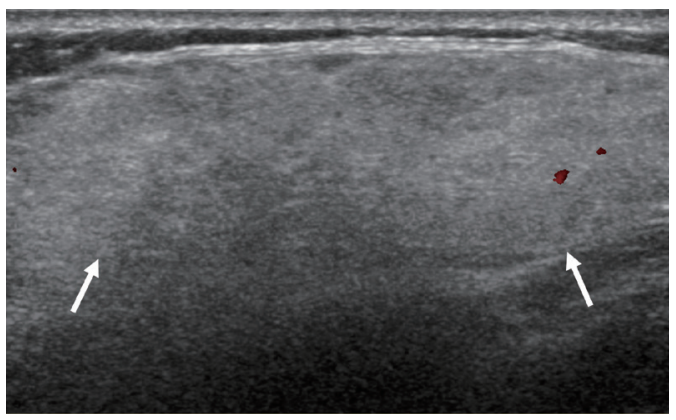

A

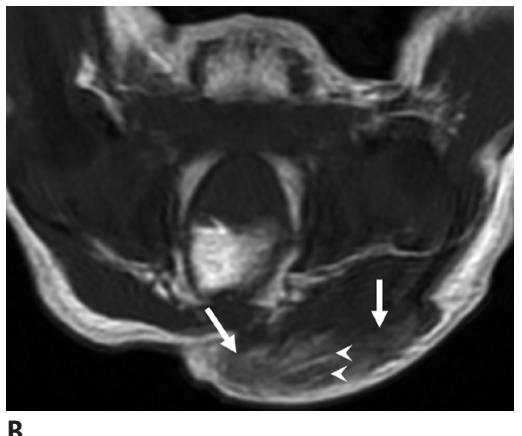

B

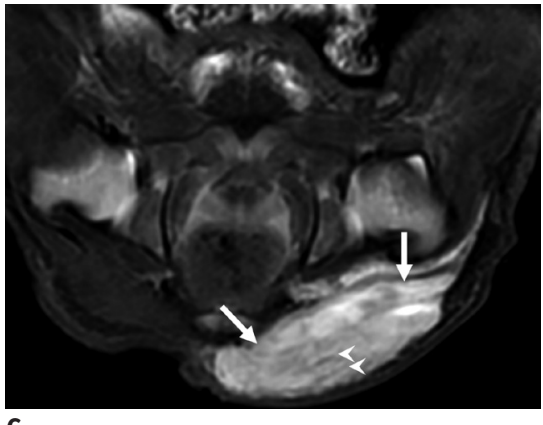

C

Fig. 9. Lipoblastoma in 5-month-old girl with gradually enlarging buttock mass from birth.

US (A) shows heterogeneous, mainly hyperechoic mass (arrows), with intervening hypoechoic areas. Axial T1-weighted MRI (B) shows welldemarcated high signal intensity mass (arrows) involving gluteus muscle and subcutaneous fat. There are some intervening hyperintense strands (arrowheads). Axial fat-suppressed T2-weighted MRI (C) shows mainly high signal intensity mass (arrows) with intervening linear hypointense strands suggesting fat component (arrowheads). 

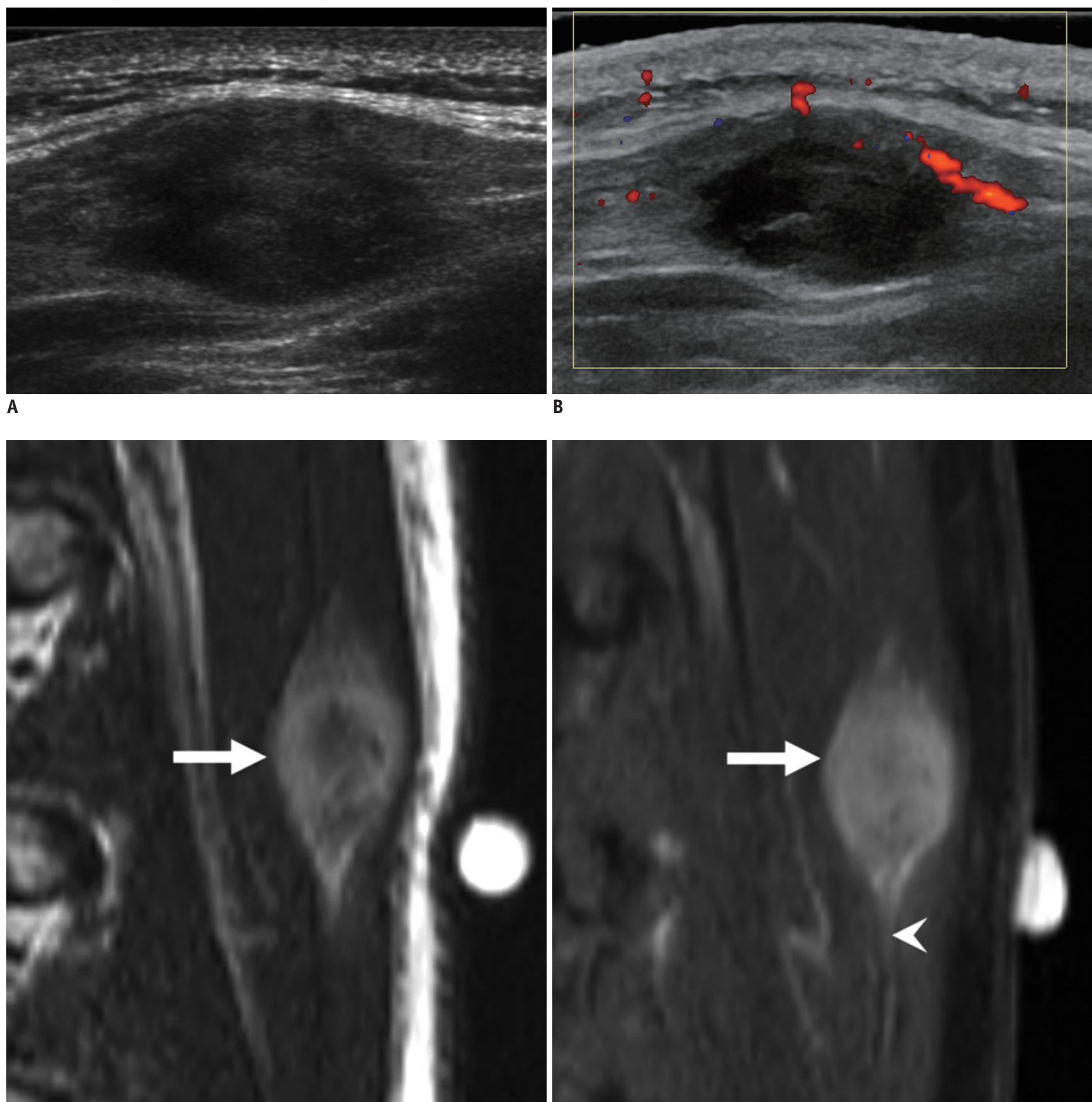

C
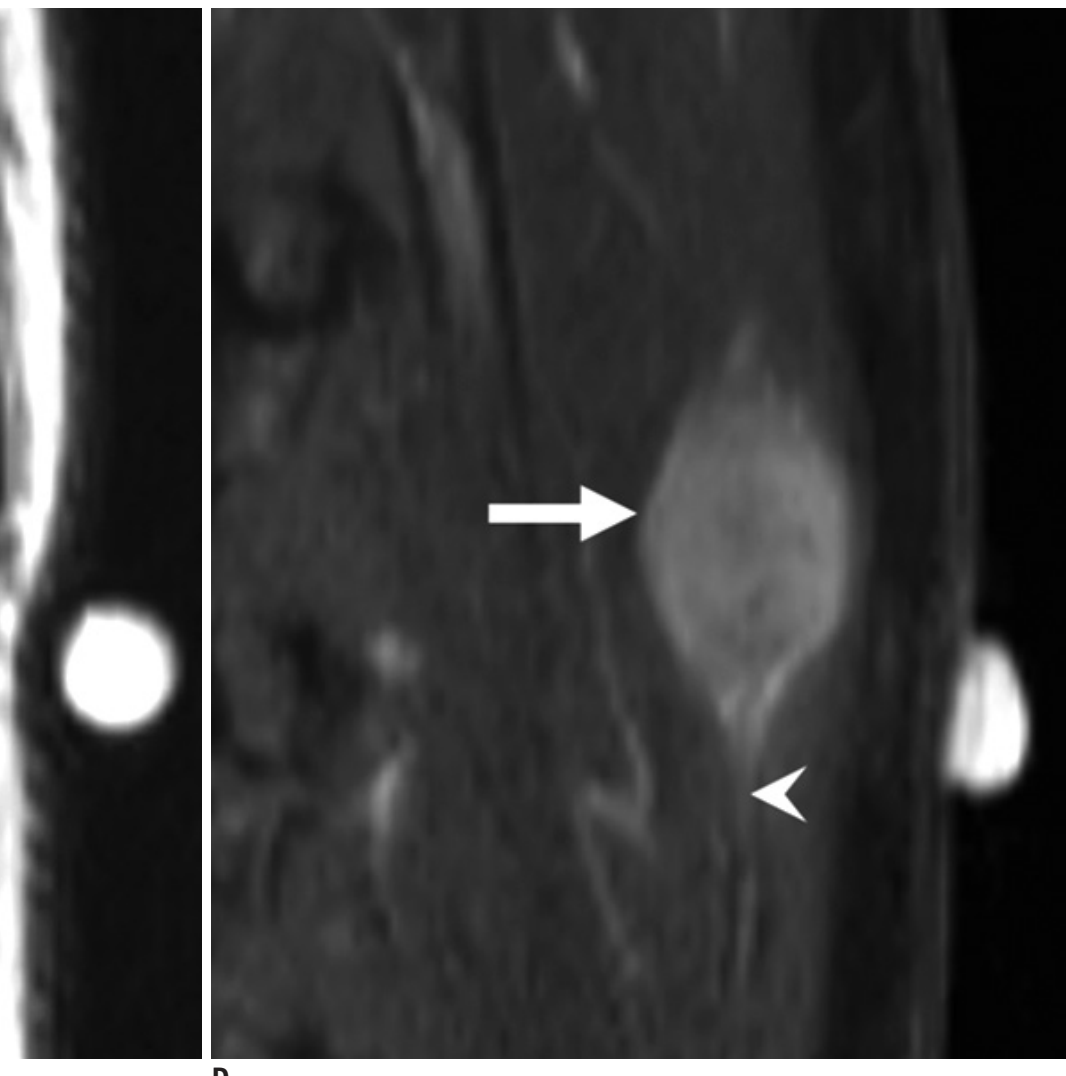

Fig. 11. Nodular fasciitis in 14-year-old boy on back.

US (A) shows well-defined ovoid hypoechoic lesion confined within muscle abutting fascia. Color Doppler scan (B) shows mild peripheral vascularity. Sagittal T2-weighted MRI (C) shows well-demarcated ovoid high signal intensity mass (arrow) within back muscle. Contrast-enhanced sagittal T1-weighted MRI (D) shows diffuse enhancement of mass (arrow) with fascial tail sign (arrowhead).

tumor or infection clinically and histologically (28-30). On US, it often appears as an ovoid mass located in the deep subcutaneous fat showing contiguity with a muscle facial plane (fascial tail sign), has a hypoechoic appearance with internal echogenic foci or peripheral hyperechoic nodules, and quite often does not show internal vascular flow (Fig.

\section{1) (28).}

Fibrous hamartoma of infancy is a rare benign softtissue tumor that usually occurs in the first 2 years of life (3). It presents as a painless mass in the subcutaneous layer and may show rapid growth. It shows ill-defined or lobulated margin located in the dermal and subcutaneous 
layer showing a combination of hyperechoic and hypoechoic area with a "serpentine pattern" due to presence of fat and fibrous tissue and poor vascularity on color Doppler (Fig. 12) (31).

\section{Pericytic (Perivascular) Tumors}

Infantile myofibroma or myofibromatosis is the most common fibrous tumors in infancy (32). They can be divided into three groups: solitary, multicentric without visceral involvement, and generalized with both cutaneous

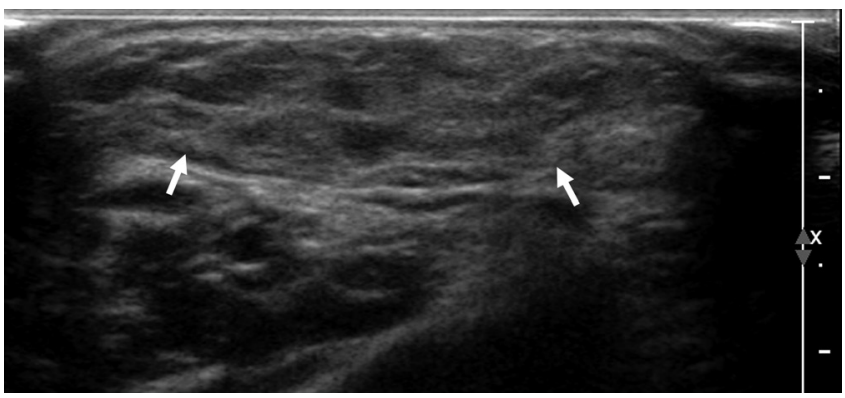

Fig. 12. Fibrous hamartoma of infancy in 8-month-old boy with slowly growing palpable lump at upper arm. US shows welldefined heterogeneous lesion (arrows) with alternating hyperechoic and hypoechoic areas.

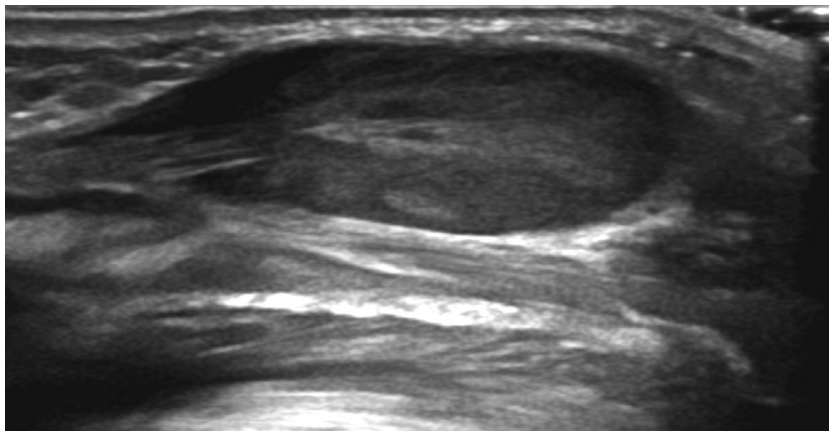

A

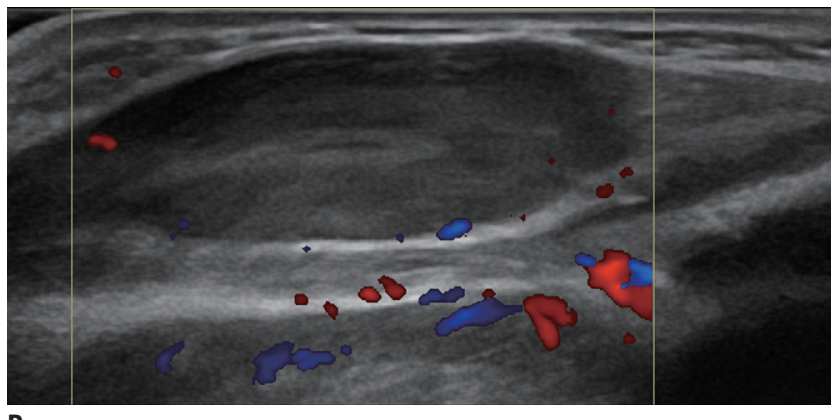

B and visceral involvement (33). The solitary type is the most common, accounting for $50-80 \%$ of all cases and the multicentric form involves the subcutaneous fat, muscle, and bone (33). On US, infantile myofibromatosis typically appears as a hypovascular solid masses with variable echogenicity (Fig. 13) and, often, anechoic central portion due to central necrosis (33).

\section{Neurogenic Lesions}

Peripheral nerve sheath tumors are benign or malignant tumors of Schwann cell origin and include schwannomas, neurofibromas, and malignant peripheral nerve sheath tumors (MPNSTs) (34). US reveals a round or oval, homogeneous hypoechoic mass relative to adjacent muscle and exhibits posterior acoustic enhancement (Fig. 14) (34). Schwannoma is rare in children and neurofibroma appears as concentric, well-demarcated hypoechoic nodular lesions that do not displace the nerve fascicle but interfere with them. Neurofibroma tends to be more homogeneous than schwannoma and may show typical feature known as "target sign." "Target sign" refers to the layered appearance of hyperechoic center and peripheral hypoechoic rim

Fig. 13. Infantile myofibromatosis in neonate presented with multiple palpable lesions.

US (A, B) shows well-defined intramuscular hypoechoic mass with minimal peripheral vascularity at forearm. Additional lesions with similar characteristic were also founded at chest wall and buttock on US (not shown). Coronal fat-suppressed T2-weighted MRI (C) shows heterogeneous hyperintense mass with central fluid signal suggesting central necrosis. Contrast-enhanced coronal T1-weighted MRI (D) shows peripheral rim enhancement of lesion. 


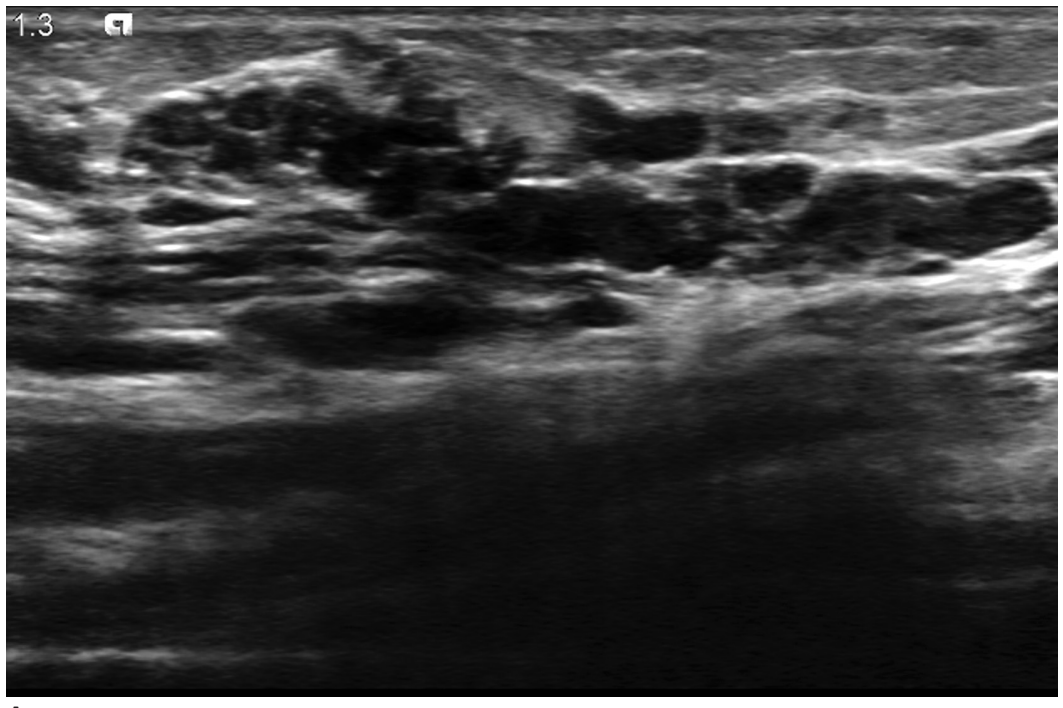

A

Fig. 14. Plexiform neurofibroma in 14-year-old girl with known neurofibromatosis type 1 and palpable masses on upper arm. US (A) shows conglomerated numerous serpiginous hypoechoic lesions at subcutaneous fat layer and muscle. Coronal T2-weighted MRI (B) shows conglomerated rounded hyperintense lesions with hypointense central foci known as "target sign" (arrows).

and it is due to the ultrastructure of neurofibroma with a fibrocollageneous center surrounded by a myxomatous periphery $(34,35)$. Plexiform neurofibroma, which is pathognomonic for neurofibromatosis type 1 , diffusely involves a nerve segment and its branches, giving a "bag of worms" appearance $(34,36)$. Malignant transformation from plexiform neurofibroma to MPNST occurs in up to $50 \%$ of neurofibromatosis patients. MPNSTs present with pain, rapid growth, and neurologic deficit $(34,37)$. While US cannot reliably distinguish benign from malignant lesions, MRI is useful in distinguishing MPNST from benign lesion with imaging features including loss of "target sign" on T2weighted image, presence of peripheral enhanced pattern, perilesional edema like zone, and intratumoral cystic lesion or necrosis (38). Increased uptake on fluorodeoxyglucosepositron emission tomography scan can also be helpful (36, $39,40)$.

\section{So-Called Fibrohistiocytic Tumors}

Giant cell tumor of the tendon sheath often appears as a painless soft-tissue mass composed of multinucleated giant cells, histiocytes, and xanthoma cells (4). On US, it is hypoechoic and appears as a well-defined mass surrounding the normal tendon and shows independent movement of the tendon and soft-tissue mass (Fig. 15) (4).

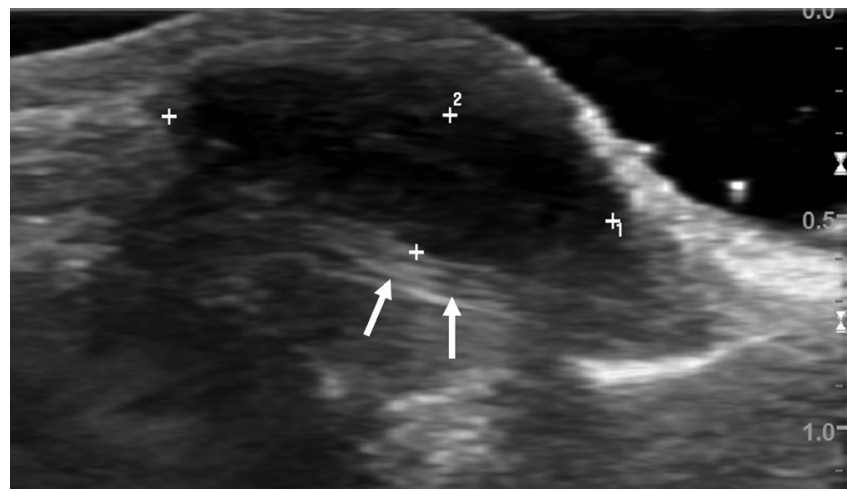

Fig. 15. Giant cell tumor of tendon sheath in 9-year-old girl with palpable mass at finger. US shows well-defined hypoechoic ovoid mass with lobulated contour at volar aspect of metacarpophalangeal joint, in close contact with but being separate from flexor tendon (arrows).

\section{Other Benign Lesions}

In children, ectodermal (epidermal and dermal) inclusion cysts are often congenital and are found in sites of embryological fusion (near sutures and midline). They contain keratin debris surrounded by a wall of stratified squamous epithelium (41). US shows well-circumscribed, ovoid-shaped, mildly echogenic masses with occasional linear anechoic and/or echogenic reflection, increased through-transmission, hypoechoic rim, and no color Doppler flow (Fig. 16). When the epidermal inclusion cysts rupture, they show lobulated shape, slightly poorly defined boundary, and intermediate grades of lesion vascularity (Fig. 
17) $(42,43)$.

Pilomatricoma is a benign, superficial tumor of the hair follicle (3). It is the third most commonly resected superficial mass in children after dermoid/epidermoid cysts and lymph nodes (3). Lesions are typically located on the

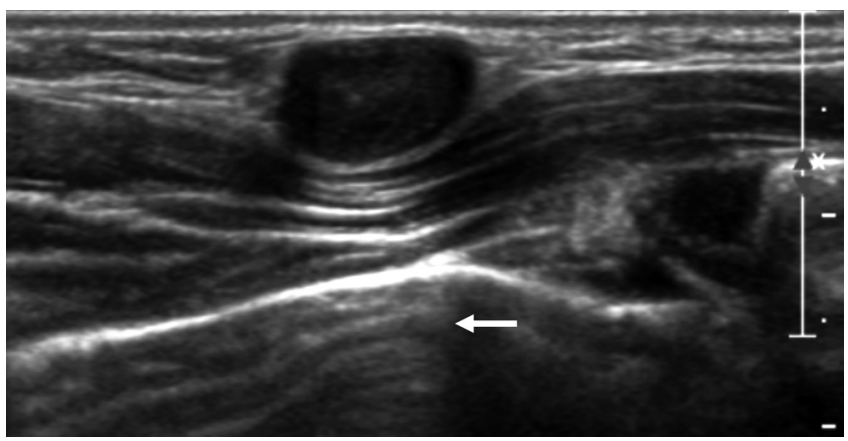

Fig. 16. Epidermal inclusion cyst in 4-year-old boy with palpable mass at chest wall. US shows well-demarcated, ovoid, hypoechoic lesion with posterior acoustic enhancement (arrow). head, neck, face, and upper extremities and are typically very hard on palpation. On US, the lesion appears as a small, ovoid, heterogeneous or predominantly echogenic mass with internal bright echogenic foci corresponding to calcification. They may show peripheral or internal flow on color Doppler imaging (Fig. 18) $(44,45)$.

Ganglia typically present with pain or palpable abnormality, most commonly on the hand or wrist (4). On US, ganglia are usually anechoic (50\%); they can be hypoechoic (35\%) (Fig. 19) or mixed anechoic and hypoechoic $(15 \%)(46,47)$. They are usually well-defined and show multiple lobulations. The most important finding is an association with joint or tendon sheath indicating the anatomic origin of the mass (6).

\section{Malignant Soft-Tissue Tumors}

Rhabdomyosarcoma (RMS) is the most common pediatric
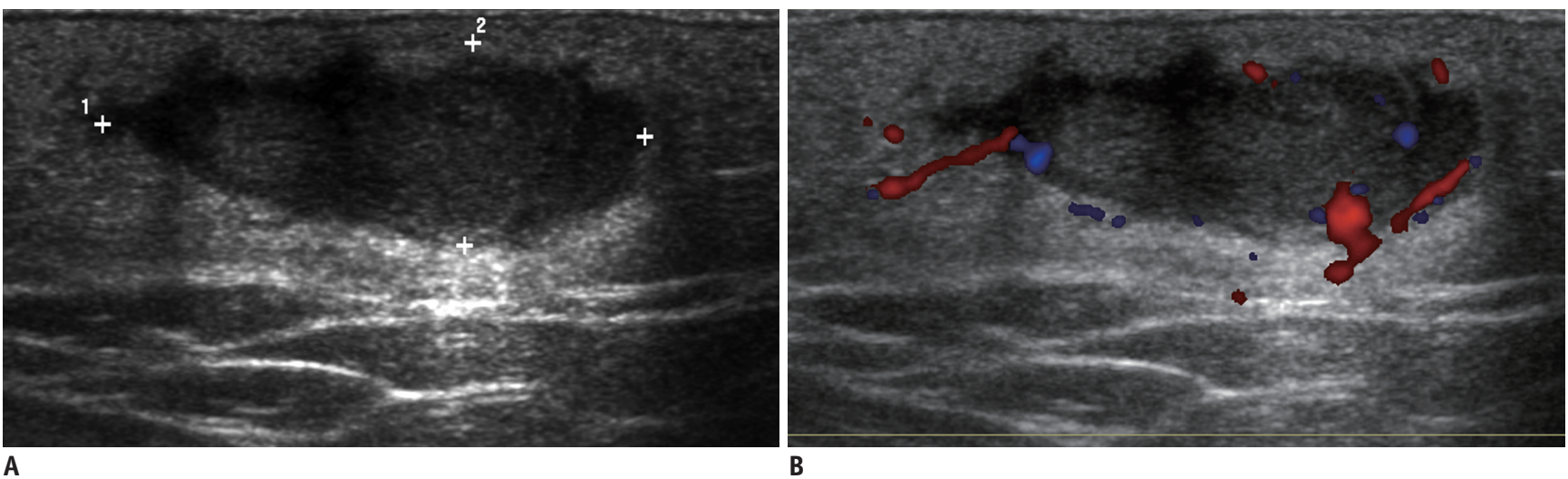

Fig. 17. Ruptured epidermal inclusion cyst in 13-year-old girl at buttock.

US (A) shows irregular low echoic nodular lesion with adjacent fat inflammation. Color Doppler scan (B) shows peripheral vascularity.
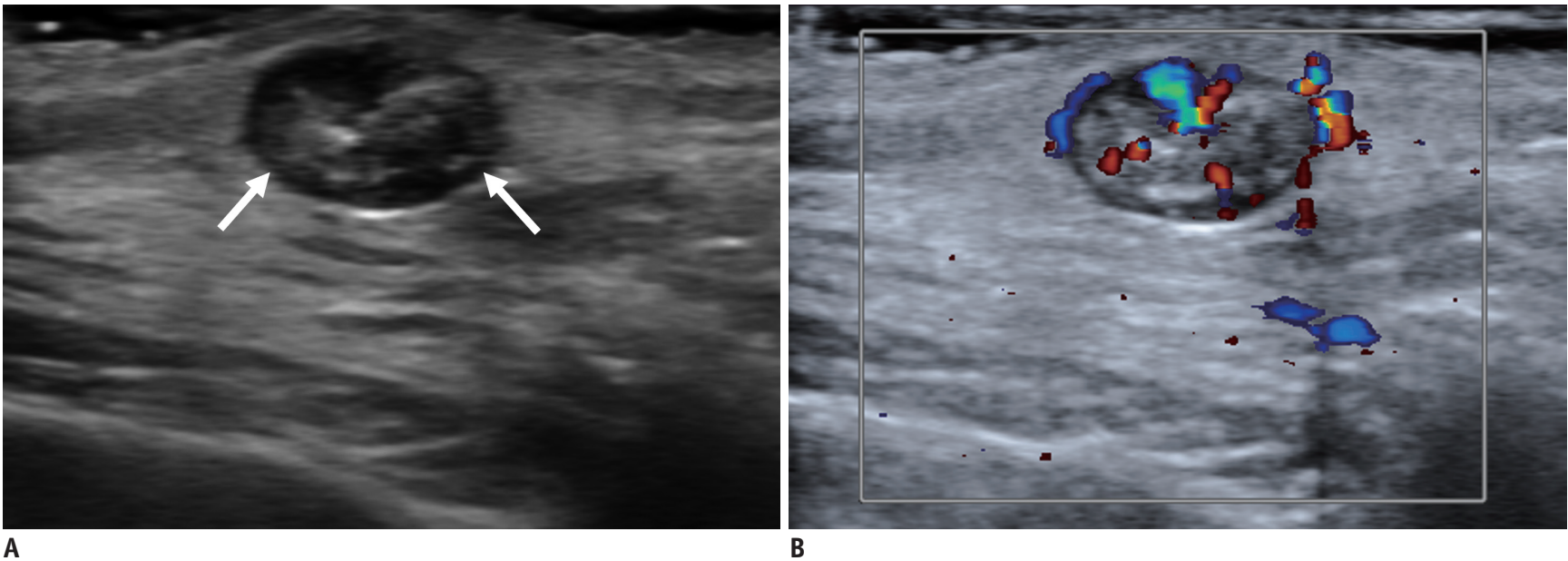

Fig. 18. Pilomatricoma in 6-year-old girl with small palpable nodule at pre-auricular area.

US (A) shows well-defined ovoid solid lesion (arrows) at subcutaneous fat layer abutting dermis. Lesion shows heterogeneous echogenicity with echogenic calcified foci and increased perilesional fat echogenicity. Color Doppler scan (B) shows peripheral and central vascularity. 


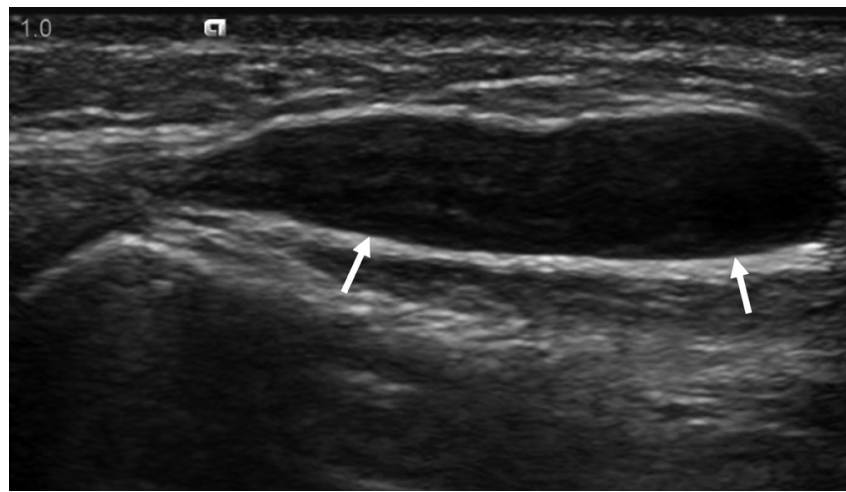

Fig. 19. Ganglion in 8-year-old girl at hand dorsum. US shows well-defined ovoid hypoechoic mass (arrows).

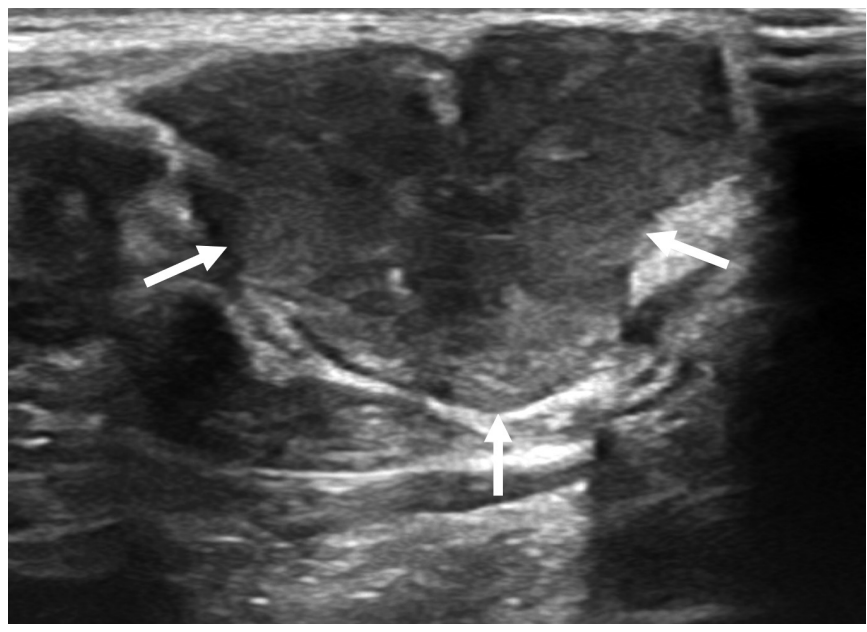

A

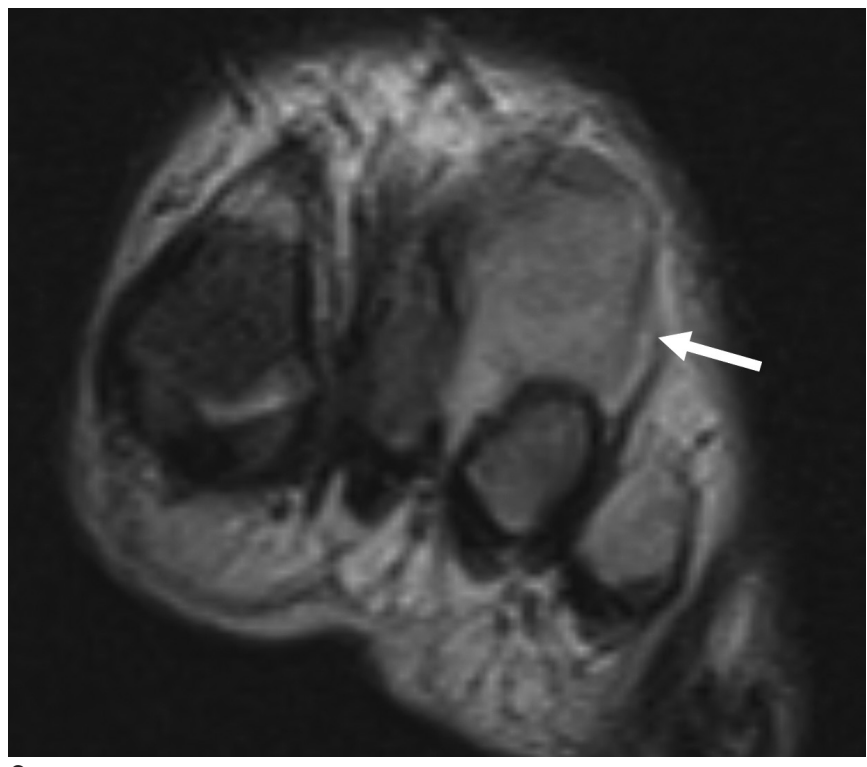

C

Fig. 20. Rhabdomyosarcoma in 11-month-old girl at foot dorsum.

US (A) demonstrates well-circumscribed, lobulating contoured, heterogeneous mass (arrows) at foot dorsum. Color Doppler scan (B) shows increased intralesional vascularity. Metastatic lymphadenopathy has found on US of left inguinal region (not shown). Coronal T2-weighted MRI (C) shows lobulated hyperintense mass (arrow). Contrast-enhanced coronal T1-weighted MRI (D) shows diffuse enhancement of lesion (arrow). Findings are not specific and histopathological findings were needed for final diagnosis. soft-tissue sarcoma $(48,49)$. On US, RMS usually appears as a well-defined, slightly hypoechoic inhomogeneous mass that can show significantly increased vascular flow on color Doppler US (Fig. 20) (48).

Synovial sarcoma, the second most common pediatric soft-tissue sarcoma, usually appears as a juxta-articular, well-demarcated, solid mass (Fig. 21) (3, 49). Typical MRI findings include a juxta-articular mass with triple signal pattern areas that are hypointense, isointense, and hyperintense to fat on T2-weighted image (50). Synovial sarcoma may sometimes be mistaken for a benign lesion when it is small at initial presentation (51).

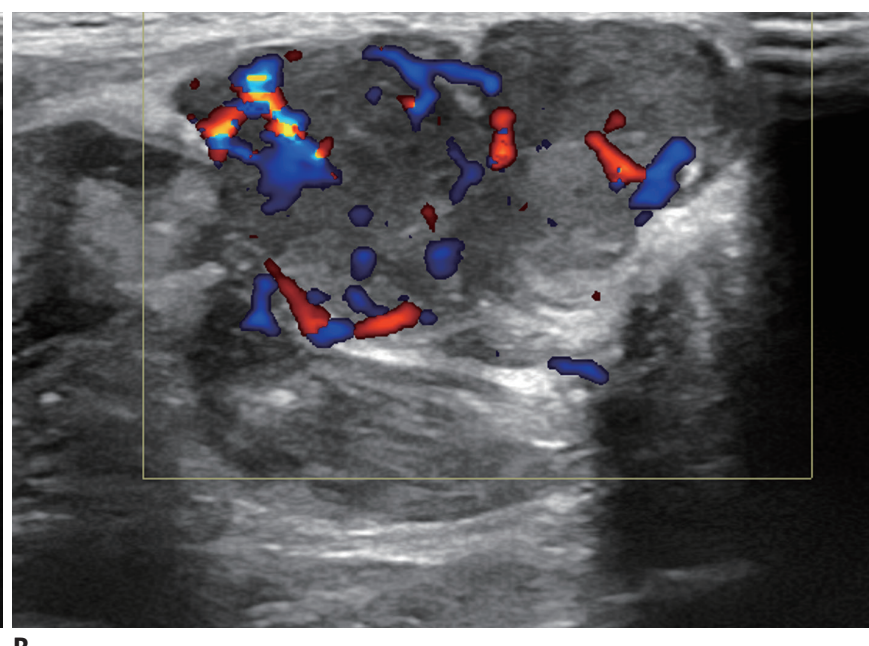

B

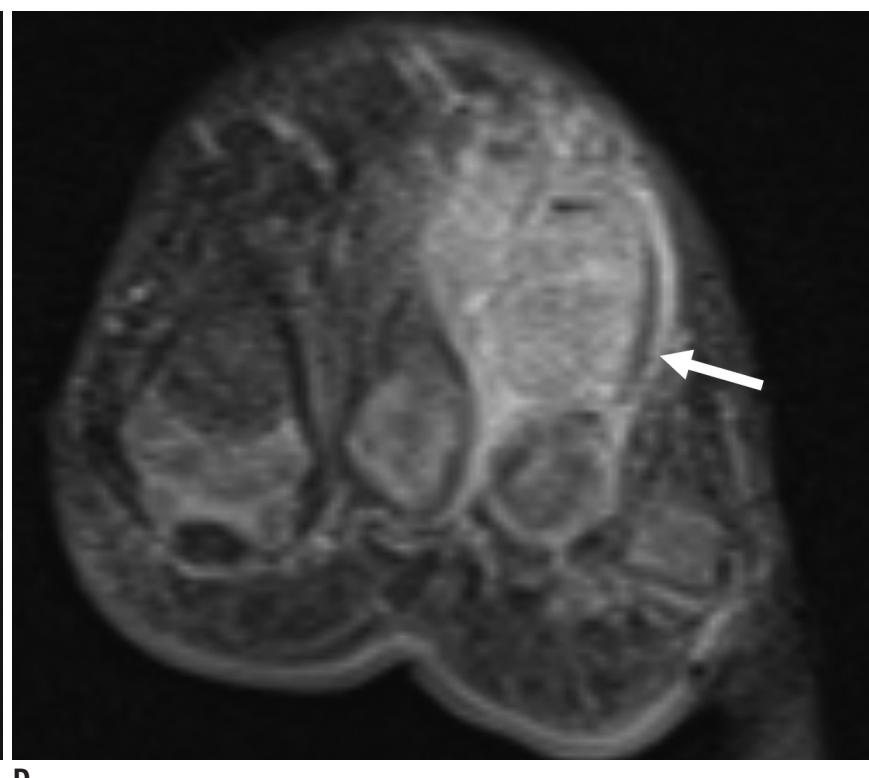

D 
Infantile or congenital fibrosarcoma is usually found in children younger than 2 years of age, accounting for $12 \%$ of soft-tissue malignancies in infancy (33). It shows much more favorable prognosis than the classic adult fibrosarcoma and frequently involves the extremities, trunk, head and neck regions. US typically shows a heterogeneous, hypervascular mass that may mimic hemangioma (Fig. 22)
(33). Subcutaneous panniculitis-like T-cell lymphoma is a rare subtype of peripheral T-cell lymphoma, presented with multiple palpable nodules on the trunk, extremities, and face (52). On US, it appears as poorly defined, hyperechoic lesions in the subcutaneous fat layer. (Fig. 23) $(52,53)$.

Multiple, subcutaneous nodules in neonates and infants should raise a concern for underlying malignancy. In a

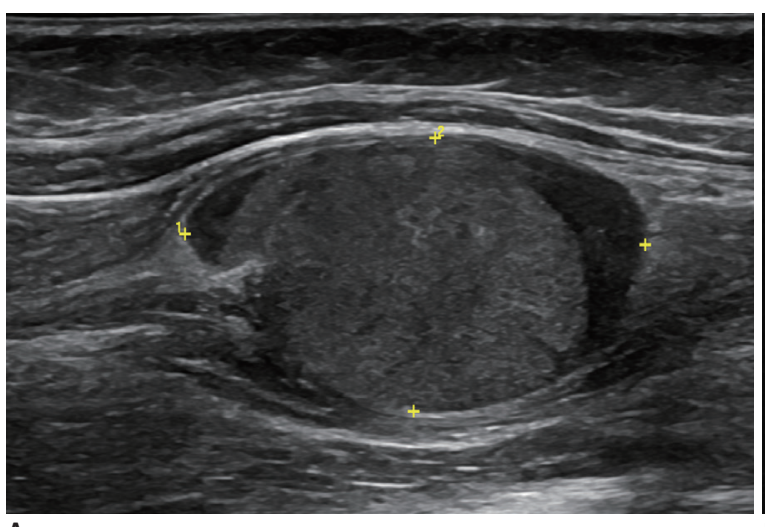

A

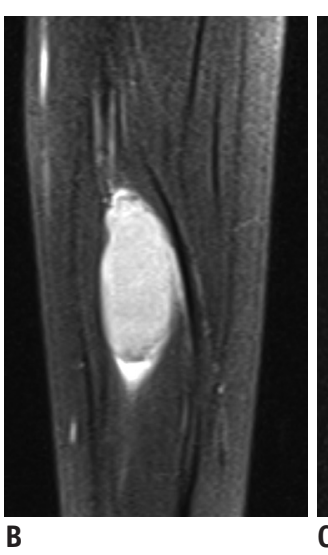

Fig. 21. Synovial sarcoma in 9-year-old girl at forearm.

US (A) shows elliptical heterogeneous hypoechoic mass within muscle. Sagittal fat-suppressed T2-weighted MRI (B) shows well-demarcated ovoid hyperintense mass. Contrast-enhanced axial T1-weighted MRI (C) shows prominent enhancement of mass.

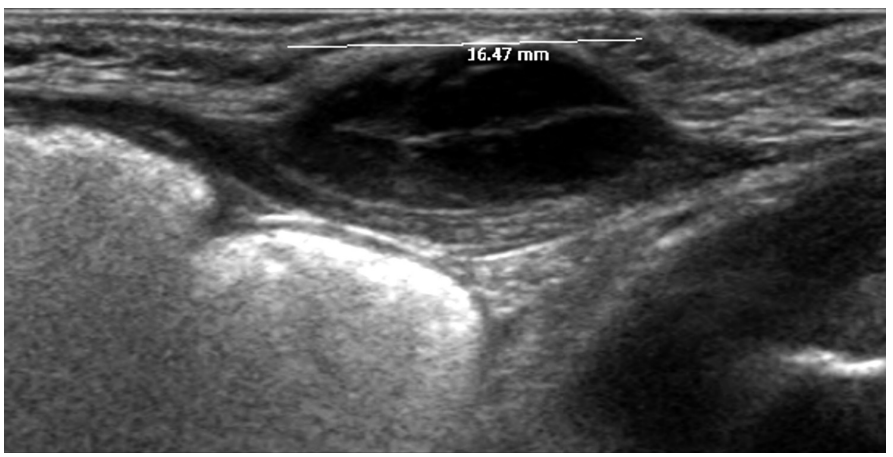

A

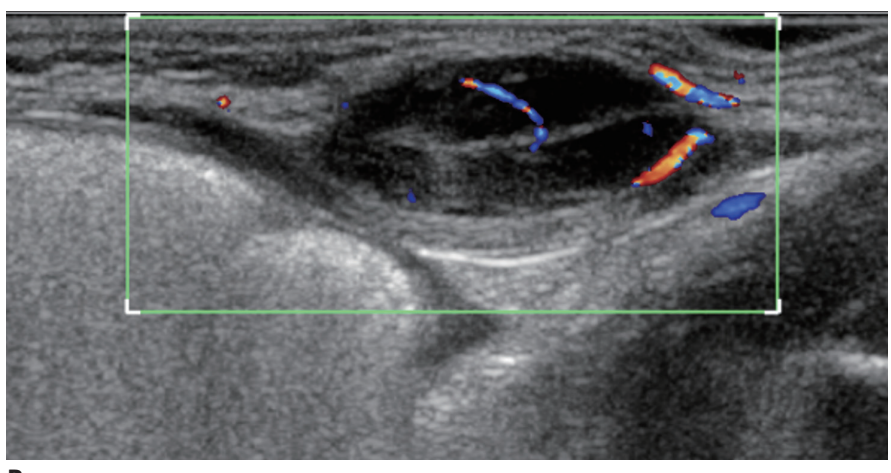

B

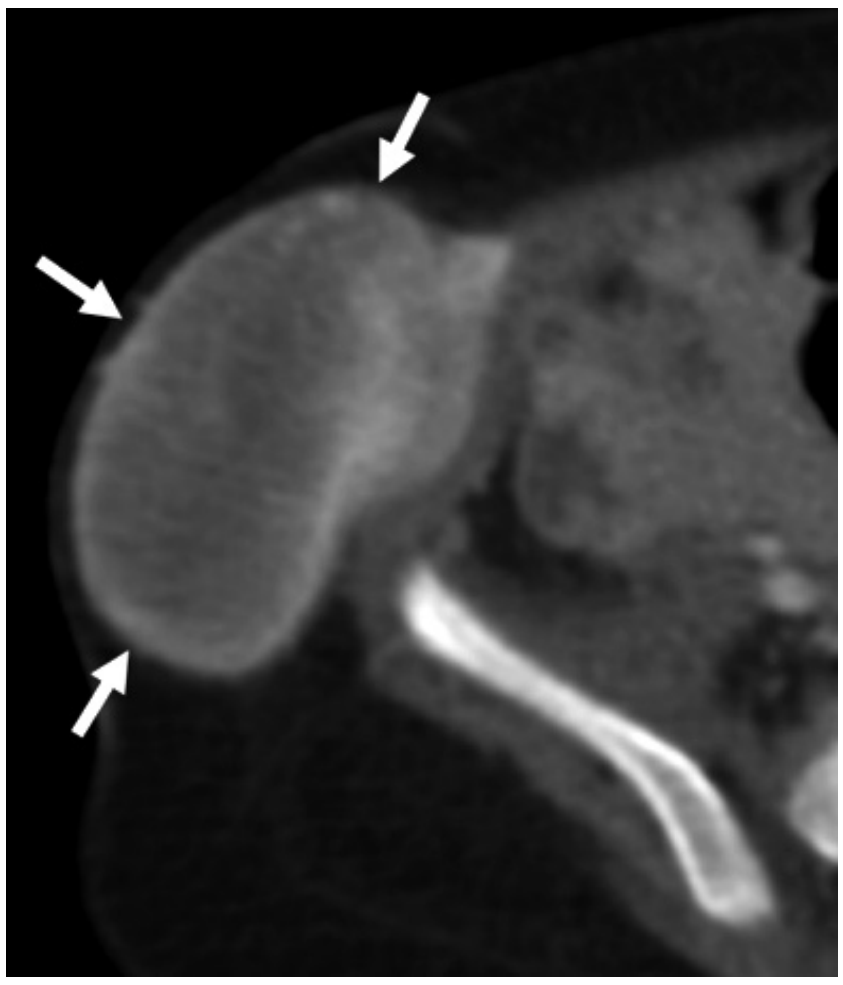

C

Fig. 22. Infantile fibrosarcoma in 1-month-old boy at abdominal wall.

US (A) shows well-demarcated ovoid hypoechoic mass at subcutaneous fat layer. Color Doppler scan (B) shows slightly increased vascularity of mass. Contrast-enhanced CT scan which was taken 5 months later (C) shows markedly increased size of mass with heterogeneous enhancement (arrows). 


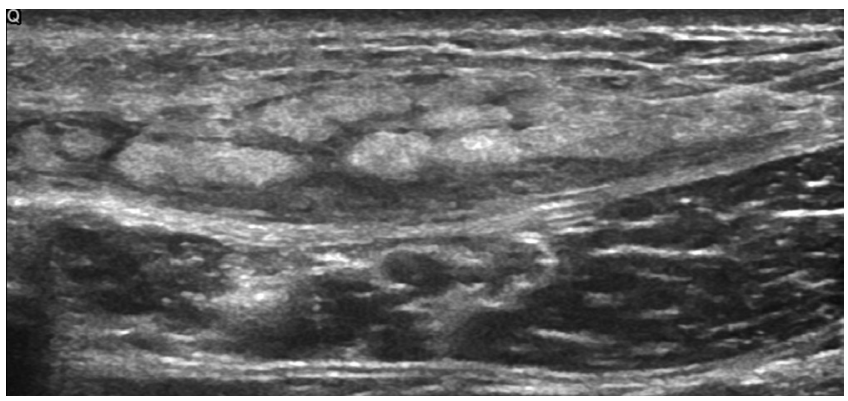

A
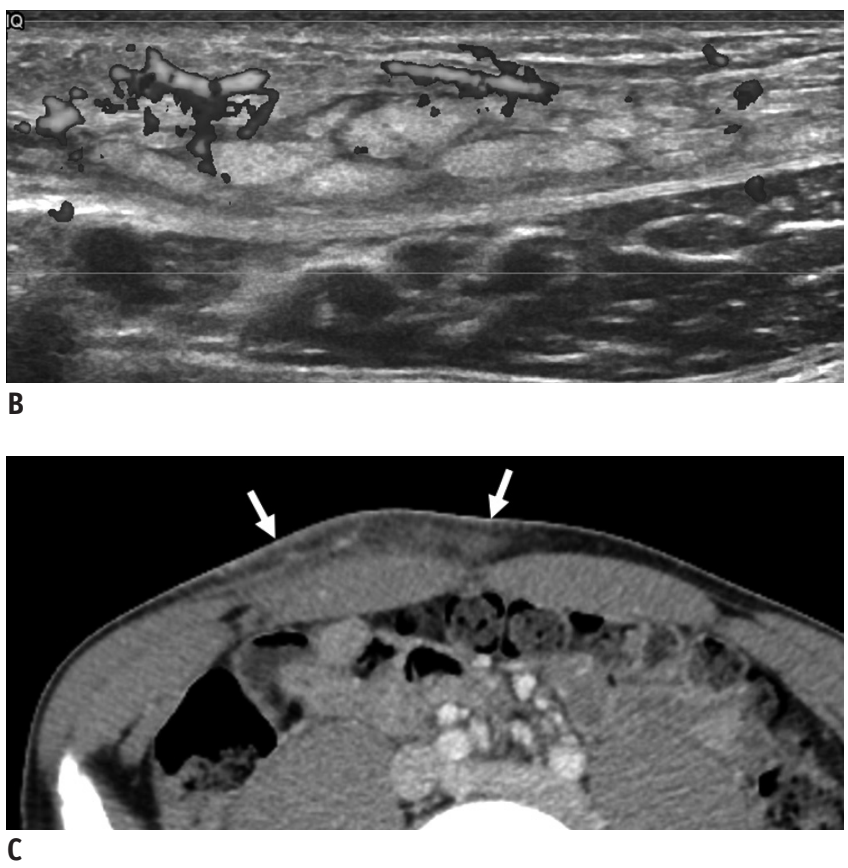

Fig. 23. Subcutaneous panniculitis-like T-cell lymphoma in 13-year-old boy with enlarging periumbilical mass.

US (A) shows diffuse ill-defined hyperechoic lesion at subcutaneous fat layer with multiple linear hypoechoic mass. Color Doppler scan (B) shows increased vascularity within area. Subsequent contrastenhanced CT (C) shows multiple enhancing nodular infiltrations at subcutaneous layer (arrows).

study of 280 neonates with cutaneous metastasis, leukemia was the most common (35\%), followed by Langerhans cell histiocytosis $(21 \%)$, neuroblastoma $(17 \%)$, rhabdoid tumor (11\%), and RMS (6\%) (54). Superficial soft tissue metastases appear as well-demarcated, hypoechoic, solid nodules in the subcutaneous fat, often simulating benign lesions due to small size (Fig. 24) $(55,56)$.

Therefore, size and margin of soft-tissue lesions are not considered as significant factors indicating malignancy. Definite benign lesions appear as a pure cyst or as a fatonly lesion (lipoma) and without such typical findings, possibility of malignancy cannot be excluded $(48,55,57$, 58). Size greater than $5 \mathrm{~cm}$, involvement of deep fascial

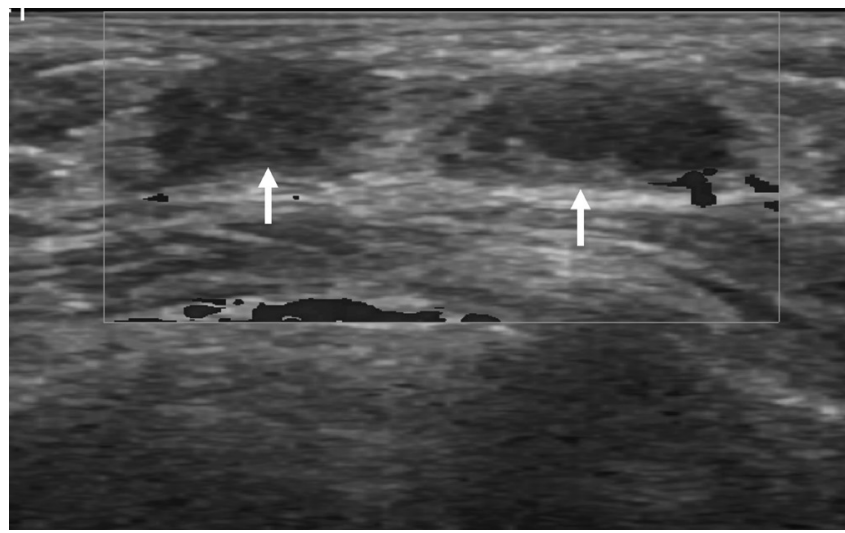

A

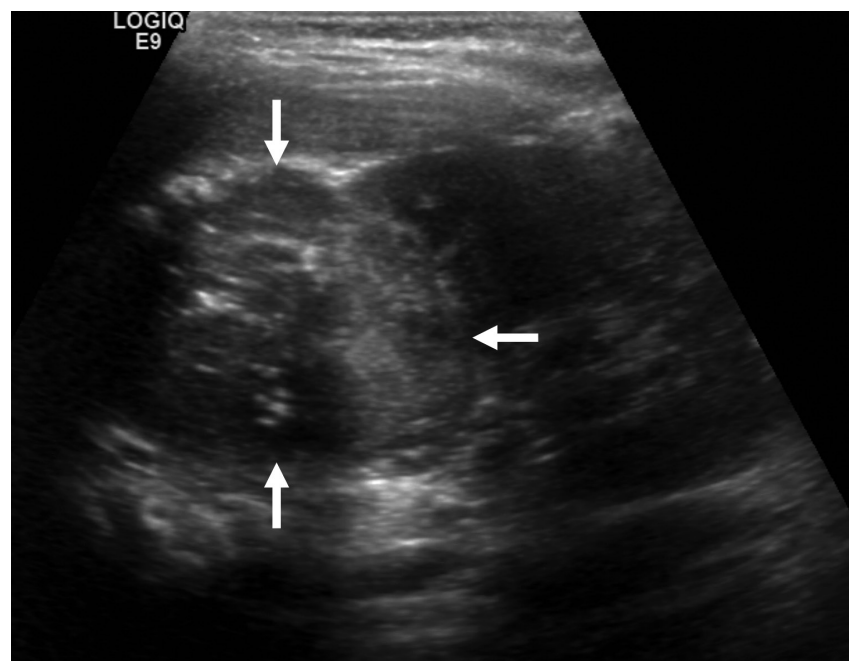

B

Fig. 24. Metastatic lesions in 3-year-old boy with adrenal neuroblastoma.

US (A) shows lobulated hypoechoic solid masses at chest wall with minimal vascularity (arrows). Abdominal US (B) shows primary tumor in left adrenal gland, neuroblastoma (arrows).

layer and the presence of internal necrosis or hemorrhage can be significant markers of malignant tumors $(58,59)$.

\section{CONCLUSION}

As a frequent initial workup of pediatric superficial softtissue tumors and tumor-like lesions, US is able to provide a specific diagnosis in some benign conditions, narrow the differential diagnosis and identify lesions which need additional imaging or biopsy, while US findings should always be considered in the context of clinical presentation. Knowledge of US technique and key imaging finding of a variety of soft tissue lesions encountered in children will facilitate establishing the correct diagnosis and guiding the management. 


\section{Conflicts of Interest}

The authors have no potential conflicts of interest to disclose.

\section{ORCID iDs}

So-Young Yoo

https://orcid.org/0000-0002-8203-3441

Hae Won Kim

https://orcid.org/0000-0001-5171-516X

Saelin Oh

https://orcid.org/0000-0002-3815-5599

Tae Yeon Jeon

https://orcid.org/0000-0002-7796-1307

Ji Hye Kim

https://orcid.org/0000-0003-3621-3406

\section{REFERENCES}

1. Beaman FD, Kransdorf MJ, Andrews TR, Murphey MD, Arcara LK, Keeling JH. Superficial soft-tissue masses: analysis, diagnosis, and differential considerations. Radiographics 2007;27:509-523

2. Wu JS, Hochman MG. Soft-tissue tumors and tumorlike lesions: a systematic imaging approach. Radiology 2009;253:297-316

3. Navarro OM. Soft tissue masses in children. Radiol Clin North Am 2011;49:1235-1259, vi-vii

4. Shah SH, Callahan MJ. Ultrasound evaluation of superficial lumps and bumps of the extremities in children: a 5-year retrospective review. Pediatr Radiol 2013;43 Suppl 1:S23-S40

5. DiDomenico P, Middleton W. Sonographic evaluation of palpable superficial masses. Radiol Clin North Am 2014;52:1295-1305

6. Carra BJ, Bui-Mansfield LT, O'Brien SD, Chen DC. Sonography of musculoskeletal soft-tissue masses: techniques, pearls, and pitfalls. AJR Am J Roentgenol 2014;202:1281-1290

7. Campbell R. Ultrasound of soft tissue masses. In: Allan PL, Baxter GM, Weston MJ, eds. Clinical ultrasound, Vol. 2, 3rd ed. London: Churchill Livingstone: Elsevier, 2011:1109-1125

8. Siegel MJ. Pediatric sonography, 5th ed. Philadelphia, PA: Wolters Kluwer, 2019

9. ISSVA classification for vascular anomalies [updated May 2018]. ISSVA, 2014. Available at: http://www.issva.org/ UserFiles/file/ISSVA-Classification-2018.pdf. Accessed September 22, 2019

10. Esposito F, Ferrara D, Di Serafino M, Diplomatico M, Vezzali $\mathrm{N}$, Giugliano AM, et al. Classification and ultrasound findings of vascular anomalies in pediatric age: the essential. $J$ Ultrasound 2019;22:13-25

11. Enjolras 0, Wassef M, Chapot R. Color atlas of vascular tumors and vascular malformations, 1st ed. Cambridge: Cambridge University Press, 2007
12. Johnson CM, Navarro OM. Clinical and sonographic features of pediatric soft-tissue vascular anomalies part 1: classification, sonographic approach and vascular tumors. Pediatr Radiol 2017;47:1184-1195

13. Olivieri B, White CL, Restrepo R, McKeon B, Karakas SP, Lee EY. Low-flow vascular malformation pitfalls: from clinical examination to practical imaging evaluation-Part 2, venous malformation mimickers. AJR Am J Roentgenol 2016;206:952962

14. Ryu YJ, Choi YH, Cheon JE, Kim WS, Kim IO, Park JE, et al. Imaging findings of kaposiform hemangioendothelioma in children. Eur J Radiol 2017;86:198-205

15. White CL, Olivieri B, Restrepo R, McKeon B, Karakas SP, Lee EY. Low-flow vascular malformation pitfalls: from clinical examination to practical imaging evaluation-Part 1, lymphatic malformation mimickers. AJR Am J Roentgenol 2016;206:940-951

16. Fishman SJ, Mulliken JB. Hemangiomas and vascular malformations of infancy and childhood. Pediatr Clin North Am 1993; 40:1177-1200

17. Johnson CM, Navarro 0M. Clinical and sonographic features of pediatric soft-tissue vascular anomalies part 2: vascular malformations. Pediatr Radiol 2017;47:1196-1208

18. Legiehn GM, Heran MK. Venous malformations: classification, development, diagnosis, and interventional radiologic management. Radiol Clin North Am 2008;46:545-597, vi

19. Flors L, Leiva-Salinas C, Maged IM, Norton PT, Matsumoto $\mathrm{AH}$, Angle JF, et al. MR imaging of soft-tissue vascular malformations: diagnosis, classification, and therapy followup. Radiographics 2011;31:1321-1340; discussion 1340-1341

20. Wassef M, Blei F, Adams D, Alomari A, Baselga E, Berenstein A, et al.; ISSVA Board and Scientific Committee. Vascular anomalies classification: recommendations from the International Society for the Study of Vascular Anomalies. Pediatrics 2015;136:e203-e214

21. Sheybani EF, Eutsler EP, Navarro OM. Fat-containing softtissue masses in children. Pediatr Radiol 2016;46:1760-1773

22. Navarro OM, Laffan EE, Ngan BY. Pediatric soft-tissue tumors and pseudo-tumors: MR imaging features with pathologic correlation: part 1. Imaging approach, pseudotumors, vascular lesions, and adipocytic tumors. Radiographics 2009;29:887906

23. Susam-Sen H, Yalcin B, Kutluk T, Cahit Tanyel F, Haliloglu M, Orhan D, et al. Lipoblastoma in children: review of 12 cases. Pediatr Int 2017;59:545-550

24. Han JW, Kim H, Youn JK, Oh C, Jung SE, Park KW, et al. Analysis of clinical features of lipoblastoma in children. Pediatr Hematol Oncol 2017;34:212-220

25. Gupta P, Potti TA, Wuertzer SD, Lenchik L, Pacholke DA. Spectrum of fat-containing soft-tissue masses at MR imaging: the common, the uncommon, the characteristic, and the sometimes confusing. Radiographics 2016;36:753-766

26. Szpecht D, Bagnosz-Magnuszewska A, Szymankiewicz M, Gadzinowski J. Subcutaneous fat necrosis in neonates after therapeutic hypothermia - report of two cases. Postepy 
Dermatol Alergol 2016;33:152-154

27. Vasireddy S, Long SD, Sacheti B, Mayforth RD. MRI and US findings of subcutaneous fat necrosis of the newborn. Pediatr Radiol 2009;39:73-76

28. Lee KJ, Jin W, Kim GY, Rhee SJ, Park SY, Park JS, et al. Sonographic features of superficial-type nodular fasciitis in the musculoskeletal system. J Ultrasound Med 2015;34:14651471

29. Khuu A, Yablon CM, Jacobson JA, Inyang A, Lucas DR, Biermann JS. Nodular fasciitis: characteristic imaging features on sonography and magnetic resonance imaging. $J$ Ultrasound Med 2014;33:565-573

30. Naidu A, Lerman MA. Clinical pathologic conference case 3: nodular fasciitis. Head Neck Pathol 2011;5:276-280

31. Lee S, Choi YH, Cheon JE, Kim MJ, Lee MJ, Koh MJ. Ultrasonographic features of fibrous hamartoma of infancy. Skeletal Radiol 2014;43:649-653

32. Chung EB, Enzinger FM. Infantile myofibromatosis. Cancer 1981;48:1807-1818

33. Sargar KM, Sheybani EF, Shenoy A, Aranake-Chrisinger J, Khanna G. Pediatric fibroblastic and myofibroblastic tumors: a pictorial review. Radiographics 2016;36:1195-1214

34. Gruber H, Glodny B, Bendix N, Tzankov A, Peer S. Highresolution ultrasound of peripheral neurogenic tumors. Eur Radiol 2007;17:2880-2888

35. Reynolds DL Jr, Jacobson JA, Inampudi P, Jamadar DA, Ebrahim FS, Hayes CW. Sonographic characteristics of peripheral nerve sheath tumors. AJR Am J Roentgenol 2004;182:741-744

36. Gosein M, Ameeral A, Banfield R, Mosodeen M. Plexiform neurofibroma of the wrist: imaging features and when to suspect malignancy. Case Rep Radiol 2013;2013:493752

37. Quinn TJ, Jacobson JA, Craig JG, van Holsbeeck MT. Sonography of Morton's neuromas. AJR Am J Roentgenol 2000;174:1723-1728

38. Wasa J, Nishida Y, Tsukushi S, Shido Y, Sugiura H, Nakashima $\mathrm{H}$, et al. MRI features in the differentiation of malignant peripheral nerve sheath tumors and neurofibromas. AJR Am J Roentgenol 2010;194:1568-1574

39. Bhargava R, Parham DM, Lasater OE, Chari RS, Chen G, Fletcher BD. MR imaging differentiation of benign and malignant peripheral nerve sheath tumors: use of the target sign. Pediatr Radiol 1997;27:124-129

40. Bensaid B, Giammarile F, Mognetti T, Galoisy-Guibal L, Pinson S, Drouet $A$, et al. [Utility of 18 FDG positon emission tomography in detection of sarcomatous transformation in neurofibromatosis type 1]. Ann Dermatol Venereol 2007;134(10 Pt 1):735-741

41. Wagner JM, Rebik K, Spicer PJ. Ultrasound of soft tissue masses and fluid collections. Radiol Clin North Am 2019;57:657-669

42. Kim HK, Kim SM, Lee SH, Racadio JM, Shin MJ. Subcutaneous epidermal inclusion cysts: ultrasound (US) and MR imaging findings. Skeletal Radiol 2011;40:1415-1419

43. Yuan WH, Hsu HC, Lai YC, Chou YH, Li AF. Differences in sonographic features of ruptured and unruptured epidermal cysts. J Ultrasound Med 2012;31:265-272

44. Hwang JY, Lee SW, Lee SM. The common ultrasonographic features of pilomatricoma. J Ultrasound Med 2005;24:13971402

45. Eutsler EP, Siegel MJ. Musculoskeletal system and vascular imaging. In: Siegel MJ, ed. Pediatric sonography, 5th ed. Philadelphia, PA: Wolters Kluwer, 2018:627

46. Teefey SA, Dahiya N, Middleton WD, Gelberman RH, Boyer MI. Ganglia of the hand and wrist: a sonographic analysis. AJR Am J Roentgenol 2008;191:716-720

47. Wang G, Jacobson JA, Feng FY, Girish G, Caoili EM, Brandon C. Sonography of wrist ganglion cysts: variable and noncystic appearances. J Ultrasound Med 2007;26:1323-1328; quiz 1330-1331

48. Van Rijn RR, Wilde JC, Bras J, Oldenburger F, McHugh KM, Merks $\mathrm{JH}$. Imaging findings in noncraniofacial childhood rhabdomyosarcoma. Pediatr Radiol 2008;38:617-634

49. Miller RW, Young JL Jr, Novakovic B. Childhood cancer. Cancer 1995;75(1 Suppl):395-405

50. Bakri A, Shinagare AB, Krajewski KM, Howard SA, Jagannathan JP, Hornick JL, et al. Synovial sarcoma: imaging features of common and uncommon primary sites, metastatic patterns, and treatment response. AJR Am J Roentgenol 2012;199:W208-W215

51. Murphey MD, Gibson MS, Jennings BT, Crespo-Rodríguez AM, Fanburg-Smith J, Gajewski DA. From the archives of the AFIP: imaging of synovial sarcoma with radiologic-pathologic correlation. Radiographics 2006;26:1543-1565

52. Kang BS, Choi SH, Cha HJ, Jung YK, Lee JH, Jeong AK, et al. Subcutaneous panniculitis-like T-cell lymphoma: US and CT findings in three patients. Skeletal Radiol 2007;36 Suppl 1:S67-S71

53. Bakst RL, Tallman MS, Douer D, Yahalom J. How I treat extramedullary acute myeloid leukemia. Blood 2011;118:37853793

54. Isaacs $\mathrm{H}$ Jr. Cutaneous metastases in neonates: a review. Pediatr Dermatol 2011;28:85-93

55. Hanna SL, Kaste S, Jenkins JJ, Hewan-Lowe K, Spence JV, Gupta M, et al. Epithelioid sarcoma: clinical, MR imaging and pathologic findings. Skeletal Radiol 2002;31:400-412

56. Giovagnorio F, Valentini C, Paonessa A. High-resolution and color doppler sonography in the evaluation of skin metastases. J Ultrasound Med 2003;22:1017-1022; quiz 10231025

57. Sood S, Baheti AD, Shinagare AB, Jagannathan JP, Hornick $\mathrm{JL}$, Ramaiya $\mathrm{NH}$, et al. Imaging features of primary and metastatic alveolar soft part sarcoma: single institute experience in 25 patients. Br J Radiol 2014;87:20130719

58. Chung HW, Cho KH. Ultrasonography of soft tissue "oops lesions". Ultrasonography 2015;34:217-225

59. Calleja M, Dimigen M, Saifuddin A. MRI of superficial soft tissue masses: analysis of features useful in distinguishing between benign and malignant lesions. Skeletal Radiol 2012;41:1517-1524 